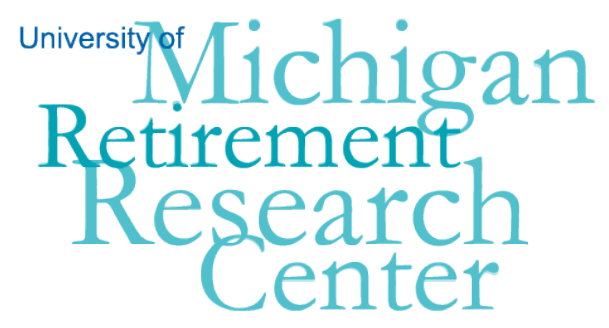

Working Paper WP 2012-274

\title{
Investment Decisions in Retirement: The Role of Subjective Expectations
}

\author{
Marco Angrisani, Michael D. Hurd and Erik Meijer
}

\begin{tabular}{c|c}
\hline $\mathrm{M}$ & $\mathrm{R}$ \\
\hline $\mathrm{R}$ & $\mathrm{C}$ \\
\hline
\end{tabular}

Project \#: UM12-13 



\title{
Investment Decisions in Retirement: The Role of Subjective Expectations
}

\author{
Marco Angrisani \\ RAND Corporation \\ Michael D. Hurd \\ RAND Corporation \\ Erik Meijer \\ RAND Corporation
}

October 2012

\author{
Michigan Retirement Research Center \\ University of Michigan \\ P.O. Box 1248 \\ Ann Arbor, MI 48104 \\ www.mrrc.isr.umich.edu
}

(734) 615-0422

\section{Acknowledgements}

This work was supported by a grant from the Social Security Administration through the Michigan Retirement Research Center (Grant \# 5 RRC08098401-04-00). The findings and conclusions expressed are solely those of the author and do not represent the views of the Social Security Administration, any agency of the Federal government, or the Michigan Retirement Research Center. 


\title{
Investment Decisions in Retirement: The Role of Subjective Expectations
}

\author{
Marco Angrisani, Michael D. Hurd, and Erik Meijer \\ RAND Corporation, 1776 Main St, PO Box 2138, Santa Monica, CA 90407-2138
}

October 31, 2012

\begin{abstract}
The rapid transition from defined benefit (DB) pension plans to defined contribution (DC) plans has a potential benefit of offering pension holders greater control over how their pension accumulations are invested. If pension holders are willing to take some risk, investments in the stock market could increase their economic preparation for retirement, and, indeed, economic theory as well as the typical advice of financial advisors calls for stock market investments. Yet, the rate of stock holding is much below what theory suggests it should be, undoing any benefit associated with the greater control coming from DC plans. The leading explanations for this under-investing include excessive risk aversion, costs of entry, and misperceptions about possible returns in the stock market. We show that excessive risk aversion is not able to account for the low fraction of stock holding. However, a model with heterogeneous subjective expectations about stock market returns is able to account for low stock market participation, and tracks the share of risky assets conditional on participation reasonably well. Based on the model with subjective expectations, we estimate a welfare loss of up to $12 \%$ compared to investment under rational expectations, if actual returns follow the same distribution as in the past 50 years. The policy implication is that there is considerable scope for welfare improvement as a result of consumer education regarding stock market returns. However, the welfare loss is much smaller if individuals are not very risk averse or if actual returns follow the same distribution as in the past 10 years.
\end{abstract}

\section{Introduction}

Standard life-cycle models of consumption and labor supply have been successfully used to evaluate possible pension system and Social Security policy changes. These models assume that individuals are forward looking and seek to maximize lifetime utility. When appropriately calibrated to capture the economic incentives of public and private pensions, they provide realistic predictions of household savings and wealth accumulation (Scholz, Seshadri, \& Khitatrakun, 2006) as well as of retirement decisions (French, 2005). On the other hand, they tend to generate investment patterns that are grossly at odds with observed portfolio choices, both inside and outside defined contribution (DC) pension plans (see, e.g., Ameriks \& Zeldes, 2004 for a description of how portfolio shares vary over the life cycle and Hung, Meijer, Mihaly, \& Yoong, 
2009 for an analysis of retirement savings management). According to a typical life-cycle model of portfolio choice (and to financial experts), retirement-age individuals should hold a substantial fraction of their wealth in risky assets. Furthermore, they should gradually reduce the share of wealth held in stocks as the risk of facing high medical expenses increases with age and negative stock market realizations cannot be as easily compensated by labor income (e.g., Cocco, Gomes, \& Maenhout, 2005). The empirical evidence is very different. In the U.S. less than $30 \%$ of retirement-age individuals hold stocks (Lee, Kapteyn, Meijer, \& Yang, 2010). Moreover, conditional on stock holding, the mean (median) share of risky assets is around 25\% (18\%) and there is no evidence of a gradual reduction in portfolio shares with age (Hurd, 2002, Korniotis \& Kumar, 2011).

Different reasons have been put forward to explain such observed patterns. For example, Heaton and Lucas (2000), Hochguertel (2003), Rosen and Wu (2004), and Curcuru, Heaton, Lucas, and Moore (2010) mention excessive risk aversion and background risks (e.g., medical costs), Alan (2006) points at startup costs of starting stock market participation, Haliassos and Michaelides (2003) study borrowing constraints, and Hong, Kubik, and Stein (2004) and Guiso, Sapienza, and Zingales (2008) propose social interaction and trust as explanations. While each of these have their merits, they do not explain empirical patterns satisfactorily and observed investment behaviors are still considered puzzling in the household finance literature (Campbell, 2006).

Recently, authors have focused on subjective equity return expectations to explain the observed low rates of stock holding (Hurd, Van Rooij, \& Winter, 2011; Kézdi \& Willis, 2008). Individual beliefs may diverge substantially from estimates of returns based on historical series. In particular, low average expectations, coupled with high uncertainty and large heterogeneity in beliefs may be the reason why so many individuals are reluctant to invest in stocks. Data eliciting subjective equity return expectations seem to support this hypothesis. Individuals on average have very pessimistic expectations about the stock market, but beliefs vary substantially across groups with different education, permanent income, cognitive functioning, numerical ability, and health status.

Assessing the importance of the various proposed reasons has important policy implications. If excessive risk aversion is the major cause, there is no obvious public policy lever that would increase participation. However, were misperceptions to be an important barrier to investing, a possible remedy would be education about the risks and rewards.

This paper quantifies the importance of knowledge about stock market rates of return in reducing stock market participation and how economic preparedness for retirement would increase were individuals fully informed about the distribution of stock market returns. We estimate the costs of misperceptions in terms of foregone rates of return and in terms of loss of lifetime utility. These costs will give an indication of the benefit that public policy might achieve. In doing so, we study an important issue that has not been addressed in the literature, namely whether a standard life-cycle model of saving and portfolio choice incorporating subjective expectations can reproduce observed investment profiles. Clearly the model would predict that individuals holding negative equity return expectations (Kézdi \& Willis, 2008) should exclusively allocate their wealth to risk-free assets. A more interesting question is which parameters of the equity return distribution would reconcile theoretical and observed portfolio patterns conditional on participation. We 
quantify what the mean and the variance of future returns are that would rationalize the observed low fractions of wealth that are invested in risky assets and how these compare with those inferred from survey questions (Dominitz \& Manski, 2007; Hurd et al., 2011; Kézdi \& Willis, 2008) and with estimates based on historical returns. We also compute to what extent they induce poor portfolio choices and what the consequences are for economic well-being.

We limit ourselves to individuals who are fully retired. The advantage of this is that retirees do not face the income risk (job loss, uncertainty about promotions, and generally future labor income) that workers face (Guiso, Jappelli, \& Terlizzese, 1996), which simplifies the model and the estimation considerably, and avoids incorrectly attributing patterns due to income risk to misperceptions about stock market risk.

The outline of the paper is as follows. In section 2, we describe the life-cycle model we use. The data, the estimation of auxiliary processes, and the sources of the baseline versions of the parameter estimates are described in section 3 . The predictions of the resulting baseline model are evaluated in section 4 . This section also explores to what extent different values of the parameters, such as risk aversion or expected stock market returns, are able to match observed patterns in the data. Section 5 discusses the survey questions that elicit subjective beliefs on stock market returns, and computes the resulting subjective distributions of stock market returns. Subsequently, section 6 computes the patterns of stock holding, wealth, and consumption that are generated by the life-cycle model with the subjective expectations governing investment decisions, and compares these with the predictions of the model using historical returns and the patterns observed in the data. Section 8 concludes.

\section{Model}

In this section, we describe a stylized model of life-cycle saving and portfolio decisions for retirees. Agents in the model choose consumption and allocate their savings between risky and risk-free assets seeking to maximize expected utility over a finite time horizon. The stock of savings comprises private wealth and non-annuitized pension wealth held in Individual Retirement Accounts (IRAs). In order to ease the notation, we suppress individual identifiers throughout the description of the model.

Preferences Age is denoted by $t$. We consider individuals who are retired, which allows us to abstract from labor income risk. They enter the model at age $t=t_{0} \in\{60, \ldots, 64\}$ and live up to age $T_{M}$. Total lifetime $T_{M}$ is stochastic, but in the model the largest allowed value of $T_{M}$ is $T=100$. Preferences are described by the time-separable iso-elastic utility function with coefficient of relative risk aversion $\gamma$ and discount factor $\beta$. Thus, the individual's expected remaining lifetime utility at age $t$ is

$$
U_{t}=\frac{C_{t}^{1-\gamma}}{1-\gamma}+\mathrm{E}_{t}\left(\sum_{j=t+1}^{T_{M}} \beta^{j-t} \frac{C_{j}^{1-\gamma}}{1-\gamma}\right),
$$


where $C_{t}$ is consumption and $\mathrm{E}_{t}$ is the expectation conditional on all information available at age $t$. In addition to the path of consumption, lifetime utility may depend on bequests. Hurd (1989) estimates a life-cycle model of consumption and finds that the marginal utility of bequests is small and, consequently, so are desired bequests. Using a model of saving for retired individuals, De Nardi, French, and Jones (2010) show that a bequest motive is only important for the richest retirees and that the average wealth profile predicted by the model is virtually unaffected by its presence. Conversely, Lockwood (2012) finds that bequests may explain why few individuals buy annuities. For the sake of simplicity, we do not include bequest motives in our model.

Health status and survival Health status at age $t$ is denoted by $H_{t}$. The individual can be either in good health, $H_{t}=$ good, or in bad health, $H_{t}=$ bad. Survival and health status evolve according to a first-order Markov process with transition probabilities that depend on age and previous year's health status. Formally,

$$
\begin{aligned}
s_{t}^{h} & \equiv \operatorname{Pr}\left(\text { alive }_{t} \mid \text { alive }_{t-1}, H_{t-1}=h\right) \\
\phi_{t}^{h} & \equiv \operatorname{Pr}\left(H_{t}=\operatorname{good} \mid H_{t-1}=h, \text { alive }_{t}\right),
\end{aligned}
$$

where $h \in$ \{good, bad $\}$. Defining

$$
S(j, g \mid t, h) \equiv \operatorname{Pr}\left(\text { alive }_{j}, H_{j}=g \mid \text { alive }_{t}, H_{t}=h\right),
$$

survival and health status probabilities are found by recursively applying $S(j$, good $\mid j-1, h)=$ $s_{j}^{h} \phi_{j}^{h}$ and $S(j$, bad $\mid j-1, h)=s_{j}^{h}\left(1-\phi_{j}^{h}\right)$. Expected remaining lifetime utility (1) can then be expressed in the form

$$
U_{t}=\frac{C_{t}^{1-\gamma}}{1-\gamma}+\sum_{j=t+1}^{T} \beta^{j-t} \sum_{g \in\{\text { good,bad }\}} S\left(j, g \mid t, H_{t}\right) \mathrm{E}_{t}\left(\frac{C_{j}^{1-\gamma}}{1-\gamma} \mid \text { alive }_{j}, H_{j}=g\right) .
$$

Retirement income In retirement, individuals receive a constant income flow, consisting of Social Security benefits, defined-benefit (DB) pensions and annuities. Retirement income is denoted by

$$
P_{t}=P, \quad \forall t
$$

In the current U.S. Social Security system, individuals can start receiving retirement benefits as early as age 62 . However, financial incentives provided by private pension plans as well as health conditions may induce earlier withdrawals from the labor force. When taking our model to the data, we will only select fully retired individuals age 60 and older. This approach greatly simplifies the model's specification. It comes at the cost of ignoring that workers on the verge of retirement may switch from full-time employment to part-time bridge jobs while receiving pension benefits.

Medical expenses In every period, agents receive health shocks and incur out-of-pocket medical expenses. The logarithm of health costs is modeled as a function of the logarithm of retirement income, age, and health status,

$$
\ln \mathrm{HC}_{t}=\delta_{0}+\delta_{1} \ln P+f\left(t, H_{t}\right)+\eta_{t}, \quad \eta_{t} \sim \mathcal{N}\left(0, \sigma_{\eta}^{2}\right) .
$$


In order to save on one additional state variable and keep the dynamic programming problem tractable, the innovations $\eta_{t}$ are assumed to be i.i.d., except that we allow the variance $\sigma_{\eta}^{2}$ to depend on health status. Hence, persistence in medical expenses is only attributable to persistence in health status and persistence in income. French and Jones (2004) show that the stochastic process for health care costs is well represented by the sum of a white noise term and a quite persistent AR(1) component. Our i.i.d. assumption may, therefore, imply an underevaluation of the duration of health cost shocks and, consequently, of the background risk associated with uncertain medical expenses.

Wealth and taxes For simplicity, we assume the existence of a single saving habitat, which comprises both conventional savings accounts and investments as well as Individual Retirement Accounts (IRAs). In the U.S. tax code, returns on savings and investment accounts are taxed, while withdrawals are tax exempt. On the other hand, returns on IRA wealth accrue tax free, while withdrawals are taxed. By combining private and IRA savings in a single stock of financial wealth, we will apply the same tax regime to both forms of savings. Our model assumes that returns are taxed at the source, but no taxes are paid when resources are used for consumption. As in the current U.S. tax code, taxes are paid on nominal rather than real returns. The marginal tax rate $\tau_{r}$ applies to nominal investment returns and the marginal tax rate $\tau_{i}$ applies to non-investment (pension) income. Since we do not distinguish between capital gains and yield on risky assets, there is no differential taxation on dividend and capital gains.

Portfolio choice The investment set is constant and consists of two financial assets: a risk-free one that can be thought of as bonds, T-bills or cash, and a risky one, representing the stock market. In each period, individuals choose the share of wealth to hold in risky assets, denoted by $\alpha_{t}$. There is no entry fee to participate in the stock market or cost associated with portfolio rebalancing ${ }^{1}$ Short sales are not allowed, and thus the following constraint is imposed:

$$
\alpha_{t} \in[0,1]
$$

Wealth dynamics We assume a constant inflation rate denoted by $\pi$. The risk-free asset yields a constant real return $r$ and thus a real after-tax return

$$
\tilde{r}=\frac{1+[(1+r)(1+\pi)-1]\left(1-\tau_{r}\right)}{1+\pi}-1 .
$$

The equity portfolio delivers a stochastic excess real return

$$
r_{t}^{e}-r=\mu+\epsilon_{t}
$$

\footnotetext{
${ }^{1}$ Market frictions in the form of fixed entry costs are often mentioned as plausible, although partial, explanations for the observed limited stock market participation. Vissing-Jørgensen (2002), Alan (2006), and Paiella (2007) all find evidence of nonnegligible entry costs. While introducing a fixed entry cost in a conventional investment account, Gomes, Michaelides, and Polkovnichenko (2009) consider stock market participation as costless in a retirement account. The idea is that informational and set-up costs associated with direct stockholding are bypassed in the latter. As the present model focuses on relatively older investors, we assume that agents have already sustained such costs earlier in their life.
} 
where $\epsilon_{t}$ is i.i.d. $\mathcal{N}\left(0, \sigma_{\epsilon}^{2}\right)$. Hence, the real after-tax return on the risky asset is

$$
\tilde{r}_{t}^{e}=\frac{1+\left[\left(1+r_{t}^{e}\right)(1+\pi)-1\right]\left(1-\tau_{r}\right)}{1+\pi}-1 .
$$

Denoting wealth with $W_{t}$, its evolution over time is described by

$$
W_{t+1}=\left[\alpha_{t}\left(1+\tilde{r}_{t+1}^{e}\right)+\left(1-\alpha_{t}\right)(1+\tilde{r})\right]\left\{W_{t}+\left(1-\tau_{i}\right) P-C_{t}-\mathrm{HC}_{t}\right\} .
$$

A borrowing constraint is present so that:

$$
W_{t} \geq 0 \quad \forall t .
$$

Since health costs are stochastic, this borrowing constraint cannot be strictly enforced unless we allow for negative consumption or censor the distribution of health costs. In practice, individuals who incur large medical expenses that cannot be covered by the value of their assets may rely on Medicaid or other means-tested government programs. In the literature, this is typically modeled as a minimum consumption floor guaranteed by public transfers. Hubbard, Skinner, and Zeldes (1995) find that such social insurance programs discourage saving at the bottom of the wealth distribution, but have little effect on the wealth accumulation trajectory of more affluent individuals. De Nardi et al. (2010) find that the size of the consumption floor greatly influences saving decisions at all levels of income. In fact, since out-of-pocket medical expenses rise with income (as they do in our model), a consumption floor constitutes a valuable safeguard against catastrophic medical costs for the wealthier. In our model, we set the consumption floor at $1 \%$ of retirement income (i.e., $0.01 P$ ). Since our focus is on portfolio choices, we intentionally choose a relatively low value for this parameter so as to minimize the "safety net" effect of the consumption floor on investment decisions. Indeed, the more generous the level of government transfers, the more shielded are the model's agents against the risk of catastrophic events (marginal utility approaching $-\infty$ ) and the more willing they become to take financial risks. In view of this, our analysis emphasizes the role of self-insurance against the risk of large medical expenses at older ages through not only a buffer stock accumulation, but also optimal portfolio rebalancing.

Very few papers have studied portfolio choices in retirement and how they are affected by the background risk of adverse health shocks resulting in high medical expenses. In the absence of unpredictable medical costs, the constraint in (12) is satisfied without introducing a minimum consumption floor (e.g., Campbell, Cocco, Gomes, \& Maenhout, 2001 and Cocco et al., 2005, among others). Yogo (2009) develops a model where retirees choose the level of health expenditure and the allocation of wealth between bonds, stocks and housing. In this setting, a consumption floor is not required since medical expenditures are endogenous and retirees are allowed to borrow against the value of the house. Hence, the focus is on how individuals can increase their lifetime horizon and self-insure against longevity risk by optimally allocating resources to different asset categories, including their health capital.

Recursive form Define cash-on-hand as the sum of liquid assets and retirement income, net of out-of-pocket medical expenses:

$$
X_{t}=W_{t}+\left(1-\tau_{i}\right) P-\mathrm{HC}_{t}
$$


The life-cycle maximization problem under consideration involves two continuous state variables — cash-on-hand and retirement income — and two discrete state variables — age and health status. As shown in the appendix, it is possible to reduce the dimensionality of the problem by dividing all variables by the constant flow of retirement income (Carroll, 1992, 1997).

Let lowercase letters indicate the ratios of the original variables to the level of retirement income (e.g., $x_{t}=X_{t} / P$ ). The individual's problem can now be written in the recursive form of the Bellman equation, after Bellman (1957)

$$
v_{t}\left(x_{t}, H_{t}\right)=\max _{c_{t}, \alpha_{t}}\left\{\frac{c_{t}^{1-\gamma}}{1-\gamma}+\beta E_{t}\left[v_{t+1}\left(x_{t+1}, H_{t+1}\right)\right]\right\},
$$

subject to

$$
x_{t+1}=\left[\alpha_{t}\left(1+\tilde{r}_{t+1}^{e}\right)+\left(1-\alpha_{t}\right)(1+\tilde{r})\right]\left(x_{t}-c_{t}\right)+\left(1-\tau_{i}\right)-\mathrm{hc}_{t+1} .
$$

Note that both $x_{t+1}$ and $H_{t+1}$ are stochastic functions of $\left\{x_{t}, H_{t}, c_{t}, \alpha_{t}\right\}$, and the survival probability is also part of the expectation.

Solution The model is solved by backward induction. The state space is given by $\left\{t, x_{t}, H_{t}\right\}$. We discretize the continuous state variable, $x_{t}$, by defining an equally spaced grid and we use two-dimensional cubic spline interpolation to construct the value function $v_{t}\left(x_{t}, H_{t}\right)$ at all points in the state space. Numerical integrations are performed by Gaussian quadrature. A solution consists of a set of policy functions for consumption and portfolio composition: $c_{t}^{*}=c\left(x_{t}, H_{t}\right)$ and $\alpha_{t}^{*}=\alpha\left(x_{t}, H_{t}\right)$. Optimal values for the choice variables are located using a combination of a root-finding algorithm and standard grid search. See the appendix for more technical details.

Optimal saving is increasing and convex in normalized cash-on-hand, which mirrors the consumption rules in Gourinchas and Parker (2002). The optimal portfolio share of the risky assets is decreasing in normalized cash-on-hand. This is because at lower levels of cash-on-hand, the risk-free asset position represented by the constant retirement income stream is relatively high and agents can tilt their portfolios more heavily towards risky investments. As cash-on-hand increases, the relative importance of retirement income on total wealth decreases and so does the optimal share of risky assets.2 It should be noted that the optimal share of risky assets is not defined for very low values of wealth at which saving is zero and no resources are available for investment.

At older ages, the optimal share of risky assets conditional on normalized cash-on-hand is lower. Since retirement benefits will be received over a shorter time horizon, the net present value of the risk-free income stream is lower and so is the willingness to bear financial risks in the form of risky investments. Also, at older ages, the risk of high out of pocket medical expenses is higher, which also leads to a less risky portfolio composition.

\footnotetext{
${ }^{2}$ As cash-on-hand increases, the optimal share of risky assets asymptotes to the value of $\mu / \gamma \sigma_{\epsilon}^{2}$. This is the constant, optimal share of risky assets generated by a portfolio model with CRRA preferences when markets are frictionless and complete and/or agents face no uncertainty about available future resources (Samuelson, 1969, Merton, 1969).
} 


\section{Data and estimation of auxiliary processes}

\subsection{Data}

We use the Health and Retirement Study (HRS; Juster \& Suzman, 1995). The HRS is a longitudinal biennial survey of individuals over the age of 50 in the U.S. and their households, which represents the primary source of information about the elderly and future elderly in the U.S. The data contain extensive information on household economic condition and demographics, individual employment history, retirement planning, pensions, and health status. We mainly use the RAND HRS (St.Clair et al., 2011), which is a postprocessed, more user-friendly version of the raw HRS data. We also add variables that are not included in the main RAND HRS file, such as subjective expectations about stock market returns (which are in the RAND-enhanced FAT files) and detailed pension data (from the RAND income and wealth imputations files). We use waves 5-10, which cover the period from 2000 to 2010.

The model as presented in section 2 is a model for the individual. In contrast with this, information on wealth and asset allocation is at the household level in the HRS. Thus, in our estimation and simulation exercises, we use the household as our unit of analysis. Wealth and income is reported by the financial respondent, who is the one deemed most knowledgeable about the household's finances. Accordingly, for some inherently individual-level variables (age, mortality), we use the variables for the financial respondent. We define an individual to be in bad health if he or she reports his or her health status as "fair" or "poor", and in good health otherwise. Because health costs are borne by the household, and economic decisions are made at the household level, the risk of health costs related to the spouse's health must be taken into account. Therefore, in our analyses, we use an indicator of bad health at the household level. The household is defined to be in bad health if either the respondent or the spouse (if any), or both are in bad health.

Out-of-pocket medical expenses comprise the costs incurred in a year for hospital, nursing home, doctor visits, dentist, outpatient surgery, average monthly prescription drug, home health care, and special facilities. Household out-of-pocket medical expenses are obtained summing the costs reported by the financial respondent and, if present, his or her spouse.

Household retirement income includes pension benefits, annuities, and Social Security retirement received by the financial respondent and his or her spouse in each wave. For each household, we first compute retirement income in each wave and then a constant flow of retirement income by averaging retirement income over all periods when it is observed.

In our baseline analysis, we adopt a very comprehensive measure of household wealth. This includes net housing wealth (primary and secondary residence, other real estate, minus balances of mortgages and other loans), vehicles, personal items of value, and net financial wealth (checking and savings accounts, certificates of deposit, bonds, stocks, businesses, IRAs, minus non-housing debt). Below we also present the results of our exercise when household wealth only comprises financial assets.

We consider stocks, held either directly or indirectly through an IRA, as the risky asset. We do not include balances in defined contribution (DC) pension plans in total wealth, nor the 
Figure 1: Stock holding and average share of risky asset conditional on stock holding among retired individuals age 60 and older in the HRS 2000-2010

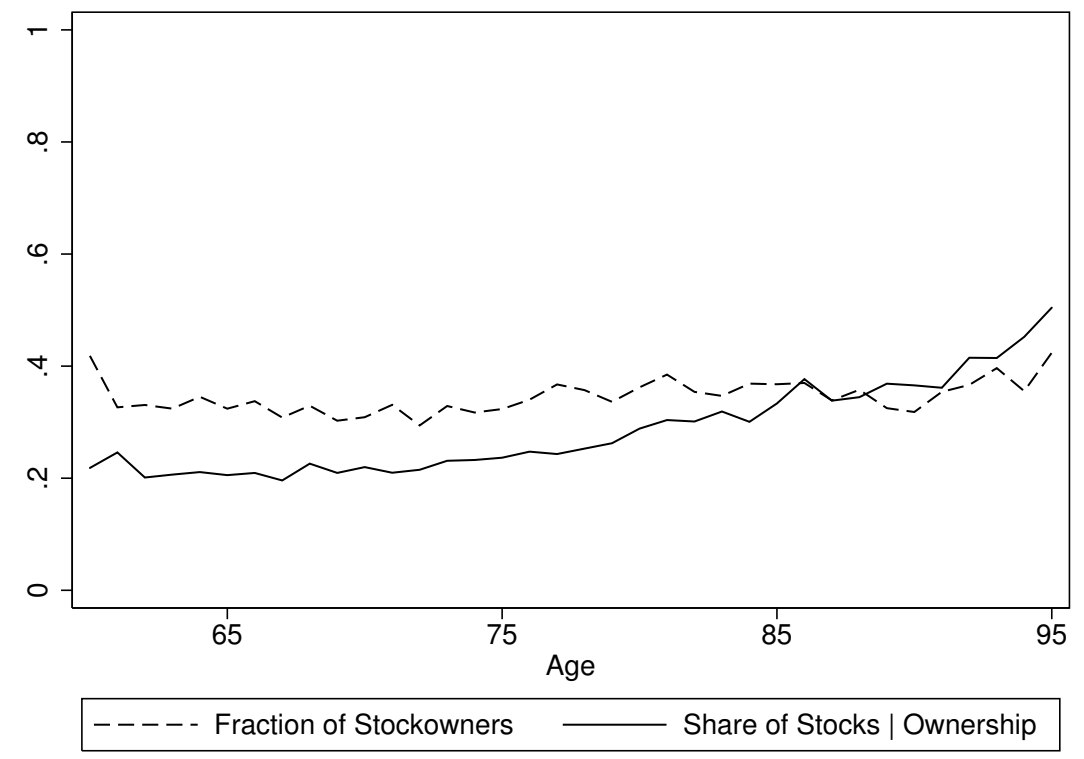

stock fraction of these balances in stock wealth, because these balances are not readily available. Gustman, Steinmeier, and Tabatabai (2010) construct measures of DC (and DB) pension wealth and the fraction of that invested in stocks. The latter is only available for 2006, in which among over 6,400 fully retired financial respondents 60 and over, less than $1 \%$ had stocks in a DC account and therefore this omission does not influence our results 3

We compute household cash-on-hand by adding household retirement income to household wealth. We divide household cash-on-hand by household retirement income to obtain the measure of normalized cash-on-hand which we use to solve and simulate the model.

We restrict our analysis to financial respondents aged 60 and older who are fully retired. We exclude households whose reported retirement income in a given wave is less than 5,000 or more than $1,000,000$ dollars per year and whose total wealth is less than 10,000 or more than $3,000,000$ dollars.

Figure 1 shows the fraction of individuals in our sample who hold stocks, and among those who hold stocks, what the average fraction of their wealth in stocks is. Stock holding is relatively constant at slightly below $40 \%$, whereas the share of risky assets slopes upward a little with increasing age. In the following sections, we will present analogous graphs based on the model predictions and compare them to this graph.

\footnotetext{
${ }^{3}$ The reasons for this are arguably that in this age group, relatively few individuals have DC plans and that upon retirement, many of those who do have a DC plan roll over their balances into an IRA or take out the pension in the form of a lump sum.
} 


\subsection{Survival and health transition probabilities}

The model has two interrelated transition processes: mortality and health transitions. We follow De Nardi et al. (2010) and others and assume that survival from age $t-1$ to age $t$, and health status at age $t$ conditional on survival, depend on health status at age $t-1$. We cannot directly estimate the one-year survival and health transition probabilities (2)-(3) from the HRS, because the HRS interviews individuals every two years and thus we do not observe one-year transitions. This is only a minor nuisance, because probabilities of two-year transitions follow from the probabilities of one-year transitions:

$$
\begin{aligned}
\Phi_{t}(\operatorname{good} \mid h) & \equiv \operatorname{Pr}\left(\text { alive }_{t}, H_{t}=\operatorname{good} \mid \text { alive }_{t-2}, H_{t-2}=h\right) \\
& =s_{t-1}^{h}\left[\phi_{t-1}^{h} s_{t}^{\text {good }} \phi_{t}^{\text {good }}+\left(1-\phi_{t-1}^{h}\right) s_{t}^{\text {bad }} \phi_{t}^{\text {bad }}\right] \\
\Phi_{t}(\operatorname{bad} \mid h) & \equiv \operatorname{Pr}\left(\text { alive }_{t}, H_{t}=\operatorname{bad} \mid \text { alive }_{t-2}, H_{t-2}=h\right) \\
& =s_{t-1}^{h}\left[\phi_{t-1}^{h} s_{t}^{\operatorname{good}}\left(1-\phi_{t}^{\text {good }}\right)+\left(1-\phi_{t-1}^{h}\right) s_{t}^{\text {bad }}\left(1-\phi_{t}^{\text {bad }}\right)\right] \\
\Phi_{t}(\operatorname{dead} \mid h) & \equiv \operatorname{Pr}\left(\operatorname{dead}_{t} \mid \operatorname{alive}_{t-2}, H_{t-2}=h\right) \\
& =1-\Phi_{t}(\operatorname{good} \mid h)-\Phi_{t}(\operatorname{bad} \mid h) .
\end{aligned}
$$

The left-hand sides of these expressions are observable in the HRS and thus can be used to estimate the one-year transition probabilities. However, the number of deaths in the HRS is insufficient to reliably estimate conditional survival rates directly. Therefore, as in De Nardi et al. (2010), we combine information from the data with unconditional survival probabilities from a lifetable and Bayes' rule to estimate conditional survival probabilities.

Specifically, we start with the 2007 Actuarial Life Table from the Social Security Administration (http://www.ssa.gov/oact/STATS/table4c6.html). We weight the male and female columns by the fraction of males and females among 60-year olds in the HRS, and then add them to obtain a combined lifetable, from which we compute the unconditional one-year survival probabilities, $s_{t}=\operatorname{Pr}\left(\right.$ alive $_{t} \mid$ alive $\left._{t-1}\right)$. Conditional survival probabilities can now be expressed using Bayes' rule as

$$
\begin{aligned}
s_{t}^{\text {good }} & =\operatorname{Pr}\left(\text { alive }_{t} \mid H_{t-1}=\text { good } ; \text { alive }_{t-1}\right)=\frac{\operatorname{Pr}\left(H_{t-1}=\text { good } \mid \text { alive }_{t}\right)}{\operatorname{Pr}\left(H_{t-1}=\operatorname{good} \mid \text { alive }_{t-1}\right)} \times \operatorname{Pr}\left(\text { alive }_{t} \mid \text { alive }_{t-1}\right) \\
& =\frac{\operatorname{Pr}\left(H_{t-1}=\operatorname{good} \mid \text { alive }_{t}\right)}{\operatorname{Pr}\left(H_{t-1}=\operatorname{good} \mid \text { alive }_{t-1}\right)} \times s_{t},
\end{aligned}
$$

and analogously for survival conditional on bad health. Thus, we estimate the numerator and denominator probabilities in (16) and compute $s_{t}^{\mathrm{good}}$ and $s_{t}^{\mathrm{bad}}$ using (16) and the results from the lifetable. It follows that we estimate four probabilities: the health transition probabilities $\phi_{t}^{\text {good }}$ and $\phi_{t}^{\text {bad }}$ from (3) and the health status probabilities $\operatorname{Pr}\left(H_{t-1}=\operatorname{good} \mid\right.$ alive $\left._{t}\right)$ and $\operatorname{Pr}\left(H_{t-1}=\operatorname{good} \mid\right.$ alive $\left._{t-1}\right)$ from 16 .

To obtain smooth estimates, we specify each of these four probabilities as a logit model with a cubic polynomial in age as covariates. We insert the resulting expressions (3) and (16) into (15) and estimate all four submodels jointly by maximum likelihood in Stata. Finally, to increase 
Table 1: Parameter estimates for the transition models

\begin{tabular}{lcc}
\hline Covariate & Coef. & s.e. \\
\hline Prob. good health $(t)$ & & \\
$a=($ Age -80$) / 10$ & $-.5861 * * *$ & $(.1619)$ \\
$a^{2}$ & -.1296 & $(.0856)$ \\
$a^{3}$ & $.1331 * *$ & $(.0662)$ \\
Constant & $1.2143 * * *$ & $(.1107)$ \\
Prob. good health $(t)$ given survival until $t$ & +1 \\
$a$ & $-.5514 * * *$ & $(.1622)$ \\
$a^{2}$ & -.1133 & $(.0858)$ \\
$a^{3}$ & $.1366 * *$ & $(.0663)$ \\
Constant & $1.2683 * * *$ & $(.1109)$ \\
Prob. good health $(t+1)$ given survival and good health $(t)$ \\
$a$ & $-.4289 * * *$ & $(.0476)$ \\
$a^{2}$ & $-.0472 * *$ & $(.0216)$ \\
$a^{3}$ & $.0459 * *$ & $(.0183)$ \\
Constant & $1.9953 * * *$ & $(.0280)$ \\
Prob. good health $(t+1)$ given survival and bad health $(t)$ \\
$a$ & .0405 & $(.0608)$ \\
$a^{2}$ & $.0605 * *$ & $(.0245)$ \\
$a^{3}$ & .0102 & $(.0232)$ \\
Constant & $-1.8134 * * *$ & $(.0332)$ \\
Sample size & & \\
\hline & &
\end{tabular}

$* * p<.05 ; * * * p<.01$.

sample size we do not impose the sample restrictions that we use in the main analyses but include all respondents 60 and over in the HRS 2000-2010. The estimation results are given in Table 1 .

Figure 2 plots the resulting one-year conditional survival probabilities $s_{t}^{h}$ and health transition probabilities $\phi_{t}^{h}$. As expected, survival probabilities drop with age, especially after age 80 or so (note that these are one-year survival probabilities, not cumulative survival probabilities), and survival probabilities are lower for bad health than for good health. The probability of staying in good health decreases a little as well, and the probability of being in good health is much lower if the individual (or household, rather) was in bad health in the previous year. Remarkably, the probability of transitioning from bad health to good health increases a little at higher ages. We suspect that this is due to relatively healthier individuals (within the "bad health" category) living longer. 
Figure 2: Conditional one-year survival probabilities and health transitions
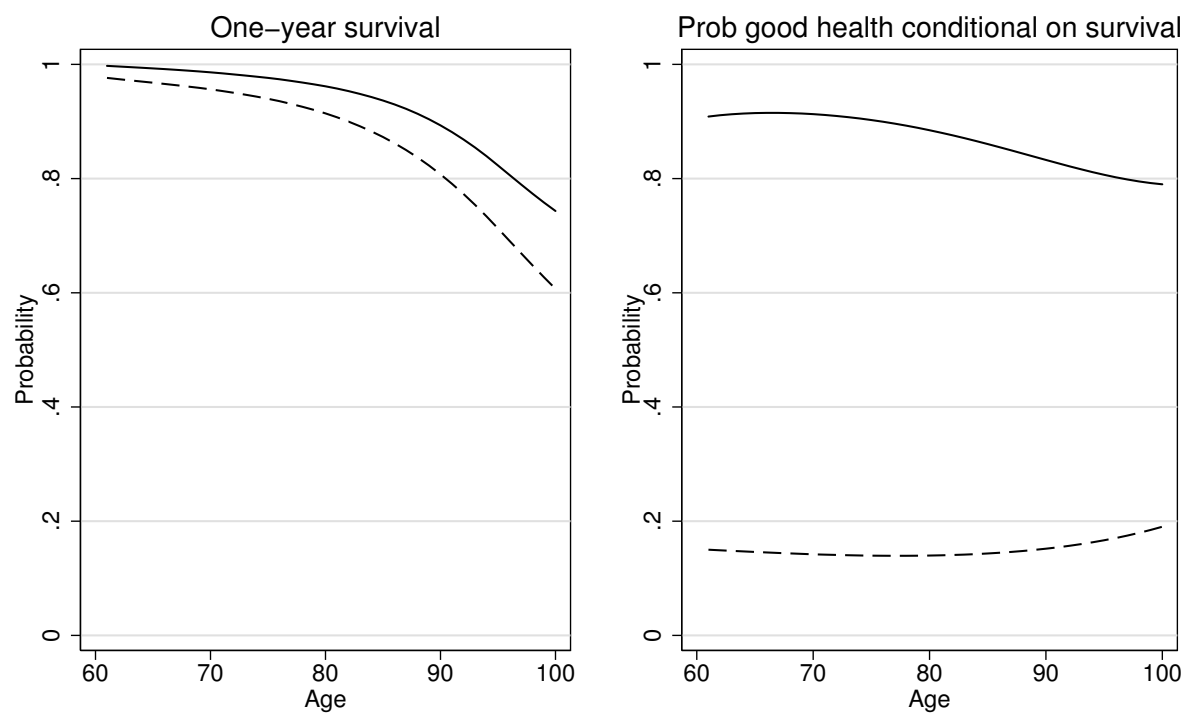

Health previous year

Good - - - - Bad

\subsection{Out-of-Pocket Medical Expenses}

As the structural model is solved in terms of normalized variables, we subtract the logarithm of retirement income from both sides of (6) and estimate a process for the logarithm of the ratio of household medical expenses to household retirement income: $\ln \mathrm{hc}_{t}=\ln \left(\mathrm{HC}_{t} / P\right)$. By assuming $\delta_{1}=1, P$ drops out of the right-hand side of the model. We specify the function $f(\cdot)$ in $(6)$ to be a third-order polynomial in age and an indicator for bad health status interacted with age. We also allow the variance of the unobserved component $\eta_{t}$ to depend on health status in order to capture differential risks for households with different health.

We include fixed effects in the model for the medical costs process to control for the potentially biasing effect of changes in sample composition with age due to differential mortality. Suppose, for example, that only wealthier households are observed at very old ages and that their ratio of medical expenses to retirement income is relatively low because of more generous pension allowances. Estimating the age profile of medical costs by pooled OLS would understate the extent to which the fraction of resources spent in health care increases with age. The fixed-effects estimator overcomes this problem. By using the time variation within each cross section, in fact, it allows us to correctly infer the age profile of household medical expenses. This also has the advantage of capturing cohort effects, which may be important for the variable of interest. If not appropriately accounted for, systematic differences in health care behavior among generations may lead to biased assessments of the age effect on household medical costs. The regressions also include year dummies, which pick up variations in medical prices that differ from inflation and 
Table 2: Estimates of the medical expenses process

\begin{tabular}{lcc}
\hline Covariate & Coef. & s.e. \\
\hline Age $^{2}$ & $0.761 * * *$ & $(0.255)$ \\
Age $^{2} / 100$ & $-0.973 * * *$ & $(0.332)$ \\
Age $^{3} / 1000$ & $0.044 * * *$ & $(0.014)$ \\
Bad Health $\times$ Age $/ 100$ & $0.374 * * *$ & $(0.029)$ \\
Year 2002 & $0.177 * * *$ & $(0.058)$ \\
Year 2004 & $0.211 * *$ & $(0.102)$ \\
Year 2006 & -0.017 & $(0.149)$ \\
Year 2008 & -0.218 & $(0.197)$ \\
Year 2010 & -0.168 & $(0.254)$ \\
Constant & $-23.017 * * *$ & $(6.676)$ \\
& & \\
Residual s.d. $\left(\sigma_{\eta}^{2}\right):$ & \multicolumn{2}{c}{$(0.027)^{a}$} \\
Good health & $1.033 * * *$ & $(0.031)^{a}$ \\
Bad health & $1.383 * * *$ & \\
Sample size & \multicolumn{2}{c}{26,050} \\
$F$-statistic fixed effects & \multicolumn{2}{c}{$3.15 * * *$} \\
\hline
\end{tabular}

$* * p<.05 ; * * * p<.01$.

${ }^{a}$ Standard errors computed by bootstrap using 1000 replications.

variations in medical costs due to other unmodeled causes, such as the business cycle.

The estimates are presented in Table 2. Figure 3 presents the estimated age profiles for the ratio of medical expenses to retirement income by health status. This is the prediction from the model except for the fixed effects and the year dummies, and reflects the predicted median health costs in 2000 by age and health status. Median health costs amount to less than $20 \%$ of income among individuals in their early $60 \mathrm{~s}$. They reach $30 \%$ for individuals in their late 80 s and rise sharply thereafter. The effect of health status on medical costs is modest until 85, but becomes substantial in the later part of the life span. These results are in line with what has been found in other studies. For example, De Nardi et al. (2010) estimate that single individuals at the median permanent income incur medical costs of roughly $\$ 1,700$ (in 2000 dollars) at age 70 and $\$ 4,500$ at age 90. Assuming that the typical household has two members and knowing that the median (constant) household retirement income is $\$ 21,000$, the implied ratios of medical expenses to permanent income are $16 \%$ at age 70 and $42 \%$ at age 90 . The estimates in the last two rows of Table 2 indicate that households in bad health face a significantly higher risk of incurring high medical costs. 
Figure 3: Medical expenses process by health status

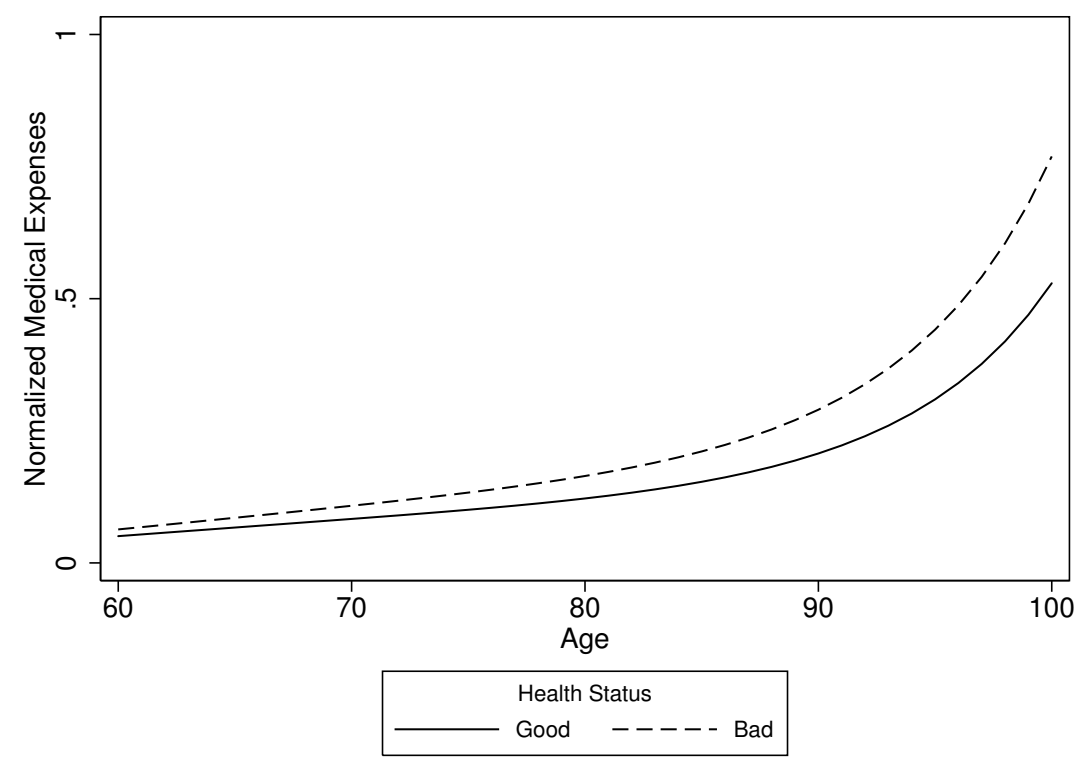

\subsection{Net asset returns and preferences}

We assume that the tax rate on retirement income $\left(\tau_{i}\right)$ is $20 \%$. The U.S. income tax code is progressive, and thus not every household faces the same average and marginal tax rates. Furthermore, tax rates change over time. The $20 \%$ rate is close to the median or mean federal income tax rate in our sample period (CBO, 2010; Piketty \& Saez, 2007). In our model, we use a tax rate on nominal asset returns $\left(\tau_{r}\right)$ of $15 \%$, which is the maximum rate on capital gains and dividends (Piketty \& Saez, 2007).

We base our parameters for asset returns and inflation on the outcomes of the past 50 years (01/01/1961-12/31/2011). From the CPI (all urban consumers, series; http://www.bls.gov/ cpi/, we derive that the average inflation rate between January 1961 and December 2011 was about $4 \%$, so in the model we take $\pi=4 \%$.

For the risk-free nominal asset return, we use the returns on 1-year Treasury Bills ( http:// www. federalreserve.gov/releases/H15/data.htm), which had an average real return of about $r=1.57 \%$.

For the risky asset returns, we use the total returns—including dividends—of the S\&P 500 (data available at http://www. econ.yale.edu/ shiller/data.htm), which had an average real return of $6.8 \%$ and, hence, a real risk premium of $5.23 \%$. In our model, we use $\mu=5 \%$ as opposed to the historical $5.23 \%$ to take into account transaction costs such as mutual fund and brokerage fees (Gomes et al., 2009). The standard deviation of the risk premium is $\sigma_{\epsilon}=0.170$, which comprises the observed historical variation in both the real risk-free and risky assets returns.

Preference parameters are taken from previous studies using life-cycle models of saving and portfolio choice. In particular, the discount factor, $\beta$, is set to 0.96, as in Cocco et al. (2005), while the coefficient of relative risk aversion, $\gamma$, to 4 , as in De Nardi et al. (2010). 
Table 3: Baseline model's parameters

\begin{tabular}{lr}
\hline Initial age & 60 \\
Final age $(T)$ & 100 \\
Discount factor $(\beta)$ & 0.96 \\
Relative risk aversion $(\gamma)$ & 4 \\
Real risk-free return $(r)$ & $1.57 \%$ \\
Mean real equity premium $(\mu)$ & $5.0 \%$ \\
Standard deviation of real risky asset returns $\left(\sigma_{\epsilon}\right)$ & 0.17 \\
Inflation $(\pi)$ & $4.0 \%$ \\
Pension income tax rate $\left(\tau_{i}\right)$ & $20 \%$ \\
Investment income tax rate $\left(\tau_{r}\right)$ & $15 \%$ \\
\hline
\end{tabular}

Table 4: Initial age and health distributions in the simulation sample

\begin{tabular}{ccllc}
\hline \multicolumn{2}{c}{ Age } & & \multicolumn{2}{c}{ Health } \\
\cline { 1 - 2 } \cline { 5 - 5 } Value & Fraction $(\%)$ & & Value & Fraction $(\%)$ \\
\hline 60 & 9.95 & & Good & 64.07 \\
61 & 13.72 & & Bad & 35.93 \\
62 & 17.60 & & & \\
63 & 27.03 & & & \\
64 & 31.69 & & \\
\hline
\end{tabular}

Table 3 summarizes the benchmark values for the model's parameters.

\section{Model predictions with historical expectations}

In this section, we describe the wealth accumulation and investment patterns obtained when agents hold rational expectations and base their estimates of future market gains on historical returns. We thus solve and simulate the model under the assumptions that (1) individuals expect that returns in the future are characterized by the parameters in section 3.4 and (2) that their expectations are fulfilled, that is, future realizations will be in line with the historical trend.

We start with the sample described in section 3.1 and select the individuals between 60 and 64 years of age. This leaves us with a pool of 3,607 individuals, from which we sample with replacement 10,000 times to obtain our simulation sample. The age and health distributions in the simulation sample are reported in Table 4. The distribution of cash-on-hand normalized to retirement income is depicted in Figure 4. 
Figure 4: Distribution of initial normalized wealth in the simulation sample

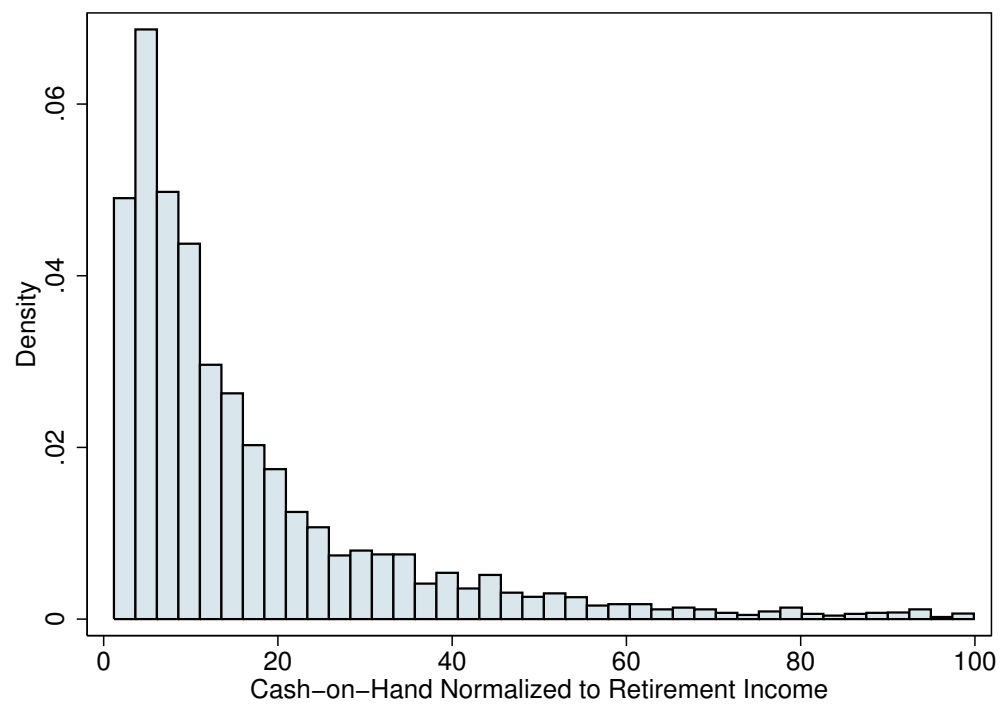

We then simulate an outcome path for each individual in the sample, where the individual uses the optimal decision rules (described above) that solve the model. Below, we report cross-sectional means of relevant variables from age 60 to age 95 . Wealth and consumption are both normalized to retirement income. Investment behavior is illustrated by the fraction of individuals who hold any wealth in stocks, and by the share of wealth held in stocks conditional on holding any. It should be noted that in our computations, we exclude those individuals who do not have enough wealth to invest and for whom the share of wealth held in the risky asset is not defined. All individuals in our simulation sample start off with enough wealth to invest. For all these individuals, the portfolio problem is correctly defined until very old ages, when asset decumulation combined with high medical expenses force some to rely on the consumption floor and, consequently, to save and invest zero.

Figure 5 shows the evolution of (normalized) consumption and wealth over the life cycle. Consumption is perfectly smooth at about 1.5 times retirement income. The initial stock of household wealth in the simulation sample amounts to about 17 times retirement income. Total wealth declines rather modestly early into retirement and starts to be largely run down in the late 70s. This is consistent with the data, where the elderly are observed to reduce their asset holdings only slightly until very late in life. As in De Nardi et al. (2010), the increase risk of unexpected large out-of-pocket medical expenses induces older households to save more for precautionary reasons and significantly slows down asset decumulation.

Figure 6 shows the fraction of retirees holding stocks and the share of wealth held in stocks conditional on stockholding. With the historical equity premium and its volatility, the model predicts that everyone should invest in stocks, which is greatly at odds with the stock market participation rate of less than $40 \%$ that we observed in the HRS (Figure 1). This finding, however, 
Figure 5: Wealth and consumption in the baseline model

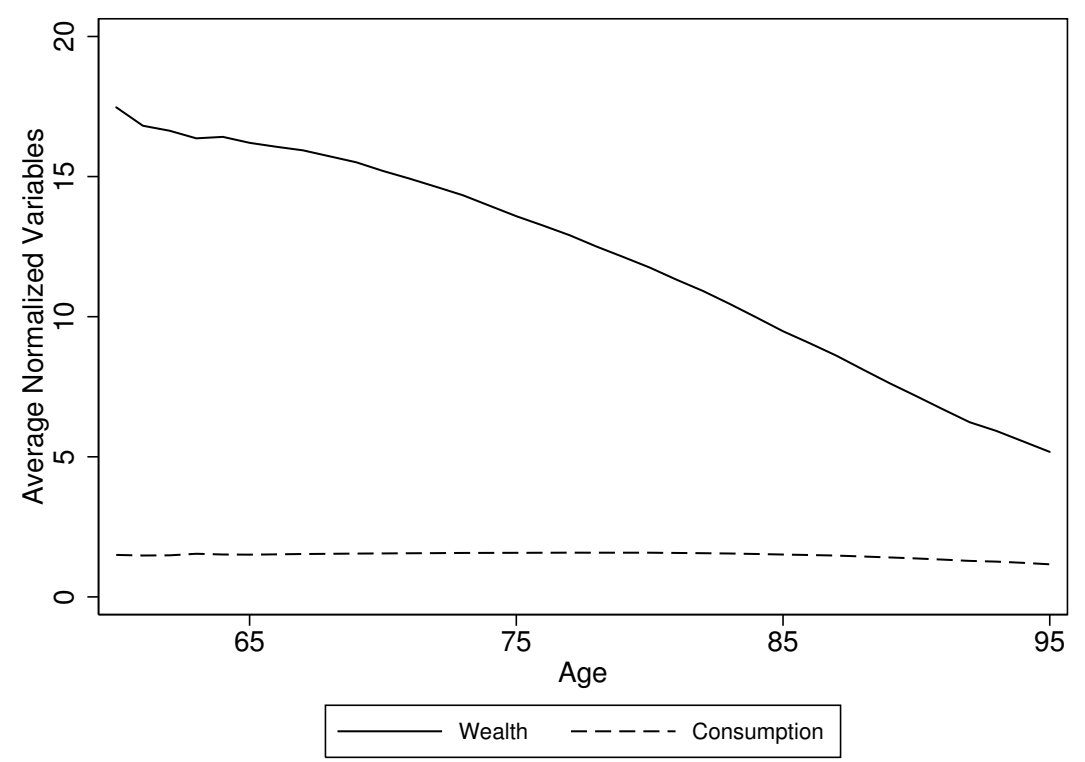

is not surprising and confirms the well-documented "stock-market participation puzzle" (Haliassos $\&$ Bertaut, 1995): under the assumption of rational expectations based on historical returns, a standard life-cycle portfolio model cannot replicate the observed low rate of household stock market participation unless it features extremely high values of risk aversion or substantial market frictions in the form of large entry and transactions costs (Alan, 2006).

The model also predicts that individuals keep most of their wealth $(75 \%)$ in risky assets at age 60 and gradually move towards more conservative portfolios as they age. This is in line with the typical financial planners' advice of shifting investments away from stocks in retirement (e.g., Cocco et al. 2005). The reason for this is that younger individuals are better able to overcome negative portfolio returns using retirement income over a longer horizon. Because the optimal share of risky assets decreases in normalized wealth, asset decumulation towards the end of the life cycle could induce a higher share of the risky assets. This mechanism is, however, counteracted by the need for hedging against the risk of large medical expenses at old ages. The net effect is a sharp decline of the fraction of wealth held in risky assets from age 85 to 95 . Again, the investment path predicted by the model is different from the empirical evidence in Figure 1. HRS respondents tend to keep around $25 \%$ of their wealth in risky assets throughout their retirement and increase this fraction to about $40 \%$ at the very end of the life cycle $4^{4}$

The model approximates the portfolio profile observed in the HRS better with alternative parameter values. For instance, Figure 7 shows that if individuals are twice as risk averse as

\footnotetext{
${ }^{4}$ Several reasons may explain the observed increase in the share of risky assets at very old ages. For example, retirees may spend down their non-equity wealth before tapping their stock market investments. Also, mortality bias may play a role, as richer and more educated individuals are more likely to hold stocks and live longer.
} 
Figure 6: Stock holding and average share of risky assets conditional on stock holding in the baseline model

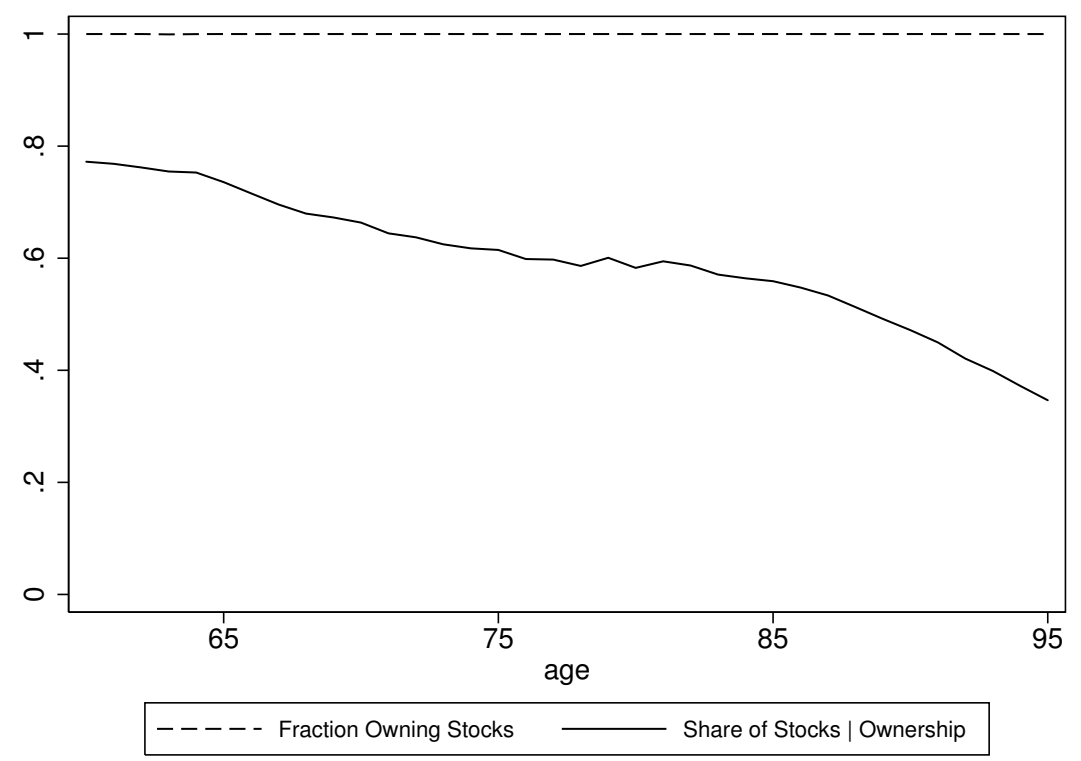

in the baseline model, the predicted share of risky assets is about $25 \%$ on average, which is much closer to the empirical pattern in the data. The need for precautionary savings increases with the degree of prudence (Kimball, 1990), which, with a CRRA utility function, is directly linked to the degree of risk aversion. For higher values of risk aversion, the preference for a buffer stock of wealth increases, inducing individuals to run down their assets more slowly and bear less financial risk by holding a more conservative portfolio. Such a high value of risk aversion, however, appears to be in contrast with empirical estimates. Hurd (1989), and Attanasio and Weber (1993, 1995), among others, find evidence of relative risk aversion as low as 1.

The investment patterns observed in the data can also be better approximated should the risk premium or its volatility differ from their historical values. Figures 8 and 9 show that if the risk premium is half the historical one or if return volatility is double the historical one, then the predicted share of risky assets is also about $25 \%$ on average. This exercise indicates the potential of using return expectations not based on historical returns to bring the model's predictions closer to observed investment patterns. We explore this possibility in the following sections.

It is worth pointing out that, even with different parameter values, the model is not able to reproduce the low fraction of stock holding that we see in the data, but predicts that all individuals should participate in the stock market. In what follows, we will document that a substantial fraction of individuals with very pessimistic beliefs about the stock market, combined with fractions of individuals with moderate or optimistic beliefs, leads to predictions that resemble the data more closely on both the intensive and extensive margins. 
Figure 7: Effect of relative risk aversion on investment behavior
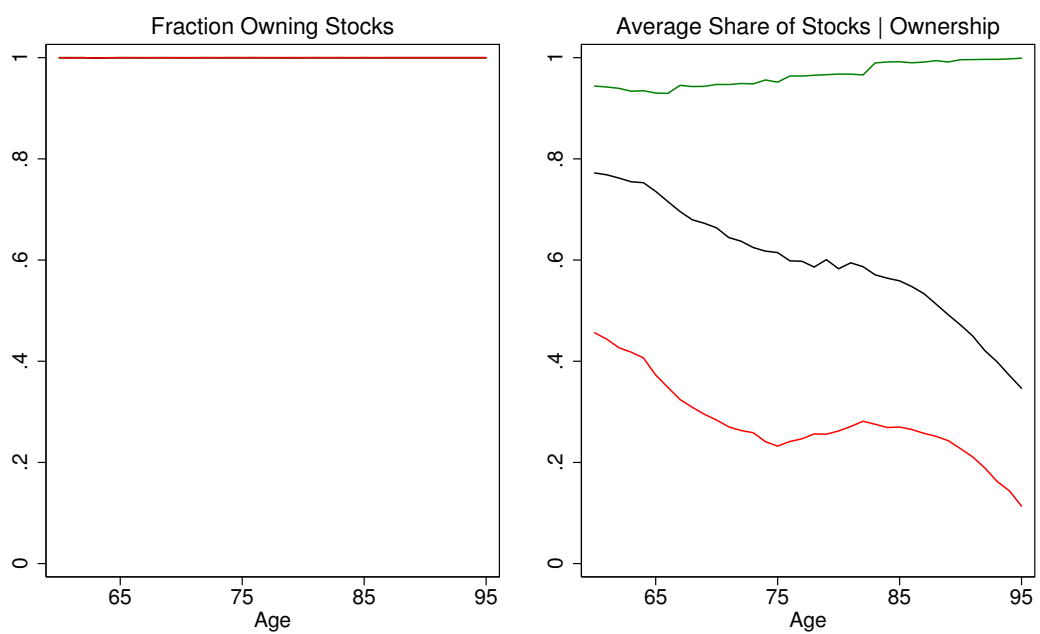

Relative Risk Aversion

$1.5-4$

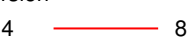

Figure 8: Effect of the risk premium on investment behavior
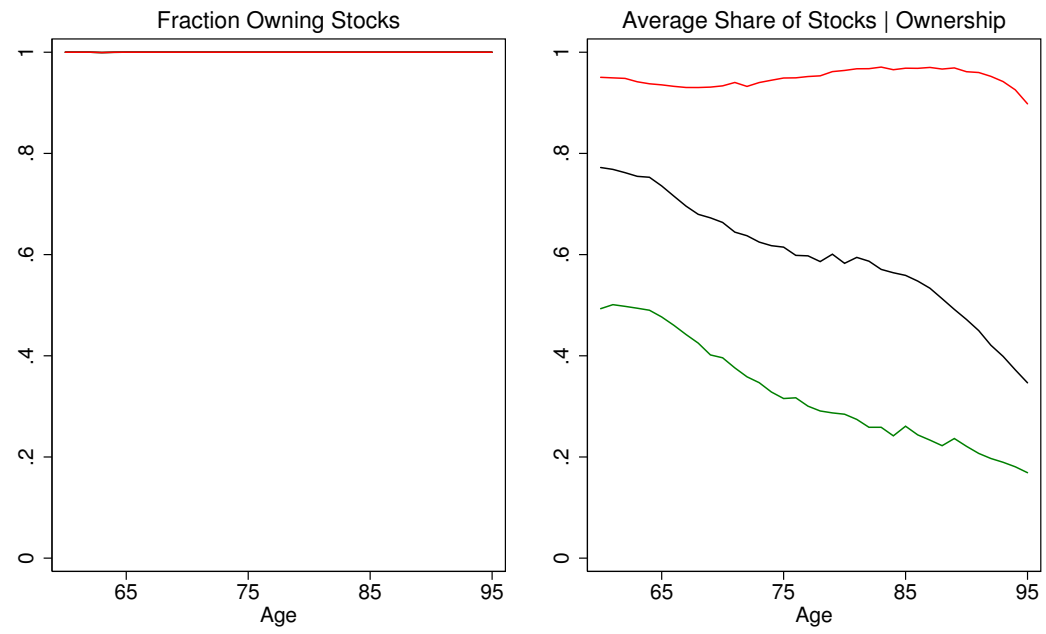

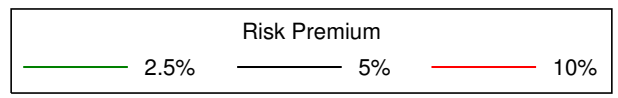


Figure 9: Effect of the return volatility (standard deviation of stock market returns) on investment behavior
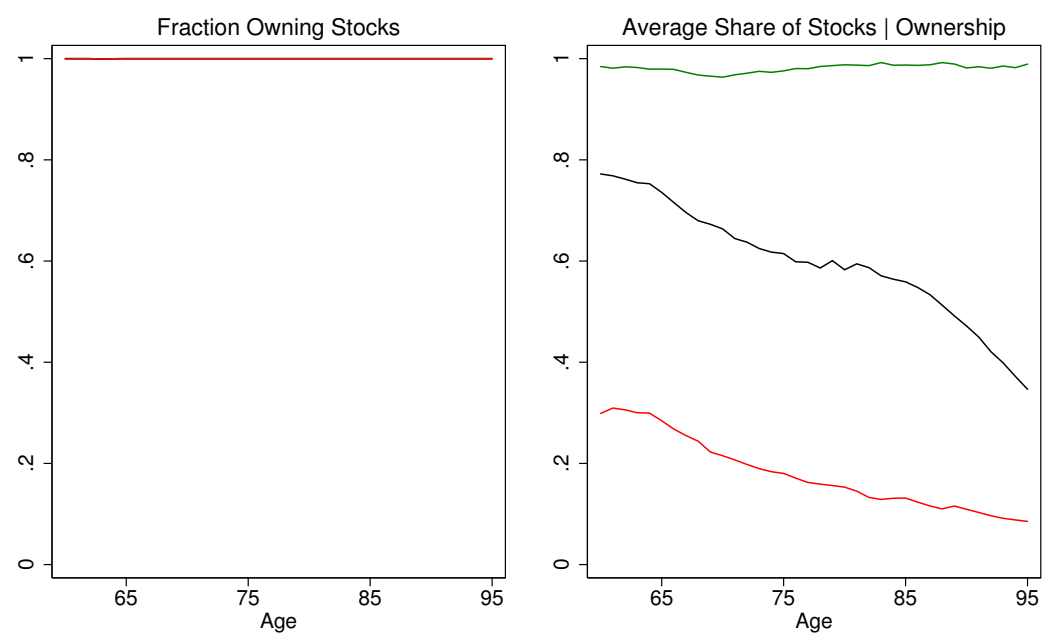

Standard Deviation of Stock Market Returns

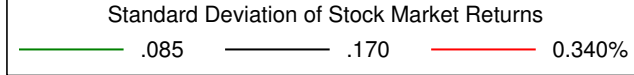

\section{Subjective beliefs about the distribution of stock market returns}

Since 2002, the HRS has elicited respondents' beliefs about stock market returns. The basic question, asked in each wave, is the following:

By next year at this time, what is the percent chance that mutual fund shares invested in blue chip stocks like those in the Dow Jones Industrial Average will be worth more than they are today?

We call this question P0. In the different waves, there are different additional questions. In 2004, only P0 was asked. In 2006 and later years, there was a follow-up question to understand whether a 50\% answer expressed epistemic uncertainty, and in 2008, there were also follow-up questions after a $0 \%$ or $100 \%$ answer to P0 to elicit whether these were rounded (in which case they were probed again to give a continuous answer) or actual beliefs of certainty. We use all this information in cases where this leads to a more informative answer to P0. In 2002, there was one additional question, which we call P10:5

By next year at this time, what is the chance they will have grown by 10 percent or more?

In 2010, two similar questions were asked (P20 and P[-20]), in which the percentage was $20 \%$ or more gain or $20 \%$ or more loss. In 2008, respondents were randomized into one of 8 follow-up

\footnotetext{
${ }^{5}$ The order of P0 and P10 was randomized, which requires slightly different wording for the two randomization groups.
} 
questions, with the same structure, with gains of 10, 20, 30, or 40\% (P10-P40) and losses of 10, 20,30 , or $40 \%(\mathrm{P}[-10]-\mathrm{P}[-40])$. So each respondent answered (at most) two questions, but overall there were nine questions. In 2006, there were additional questions about 10 years in the future and about the past 10 years. Because these ask about a different distribution, we do not use the latter.

Summarizing, for the distribution of the one-year ahead stock market return, respondents gave one probability in 2004 and 2006, up to two probabilities in 2002 and 2008, and up to three probabilities in 2010. Under suitable assumptions, we can use these self-reported probabilities to compute individual-specific distributions of stock market returns. Throughout, we assume that these questions elicit beliefs about nominal before-tax returns.

Dominitz and Manski (2007) studied the 2004 data, which only had P0. They assumed that respondents' subjective distributions of stock market returns are normal distributions, and that the standard deviation of this distribution is the same as the standard deviation of historical nominal returns (for which they use 0.206). These assumptions can be used to compute the subjective mean. Let $m_{i}$ be respondent $i$ 's subjective mean, $s_{i}=0.206$ be respondent $i$ 's subjective standard deviation, and $p_{0 i}$ be the answer to P0 divided by 100 . Then $m_{i}=-s_{i} \Phi^{-1}\left(1-p_{0 i}\right)$, where $\Phi(\cdot)$ is the standard normal cumulative distribution function. This method can be used for the 2004 and 2006 data. If there is more information, this method can be generalized. In years where the respondent gave two answers, we can drop the assumption about $s_{i}$ and solve the system of two equations in two unknowns. Let the two probabilities be denoted by $p_{x i}$ and $p_{y i}$, corresponding to a stock market gain of at least $x$ and $y$ (e.g., $x=0$ and $y=0.10$ in 2002). In the case of losses, first transform the answer from $\mathrm{P}[-x]$ to $100-\mathrm{P}[-x]$. Then

$$
\begin{aligned}
s_{i} & =\frac{y-x}{\Phi^{-1}\left(1-p_{y i}\right)-\Phi^{-1}\left(1-p_{x i}\right)} \\
m_{i} & =x-s_{i} \Phi^{-1}\left(1-p_{x i}\right)=\frac{x \Phi^{-1}\left(1-p_{y i}\right)-y \Phi^{-1}\left(1-p_{x i}\right)}{\Phi^{-1}\left(1-p_{y i}\right)-\Phi^{-1}\left(1-p_{x i}\right)} .
\end{aligned}
$$

With three answers, we have a system of three equations in two unknowns, and we have to compute some kind of compromise value. A simple method would be to compute the $m_{i}$ and $s_{i}$ resulting from applying (17) to the smallest two values of $x$ (i.e., P0 and the loss question) and compute another $m_{i}$ and $s_{i}$ resulting from applying (17) to the largest two values of $x$ (i.e., P0 and the positive gain question) and taking the average of the two.

Hurd and Rohwedder (2011) take a different approach. They observe that if the respondent answers $k$ questions, we have the probabilities associated with $k+1$ mutually exclusive intervals that span the whole real line. They proceed to assume that the subjective distribution within each interval coincides with the historical distribution within that interval. For example, suppose the respondent answers only P0. From this we can deduce $\operatorname{Pr}_{i}(n<0)$ and $\operatorname{Pr}_{i}(n \geq 0)$, where $n$ is the nominal return and the subscript $i$ denotes respondent $i$ 's subjective distribution. Then

$$
\begin{aligned}
\mathrm{E}_{i}(n) & =\operatorname{Pr}_{i}(n<0) \mathrm{E}(n \mid n<0)+\operatorname{Pr}_{i}(n \geq 0) \mathrm{E}(n \mid n \geq 0) \\
\mathrm{E}_{i}\left(n^{2}\right) & =\operatorname{Pr}_{i}(n<0) \mathrm{E}\left(n^{2} \mid n<0\right)+\operatorname{Pr}_{i}(n \geq 0) \mathrm{E}\left(n^{2} \mid n \geq 0\right) .
\end{aligned}
$$


The conditional expectations on the right-hand side are taken from historical distributions, and the subjective mean and standard deviations are obtained as $m_{i}=\mathrm{E}_{i}(n)$ and $s_{i}=\left[\mathrm{E}_{i}\left(n^{2}\right)-m_{i}^{2}\right]^{1 / 2}$. This method immediately generalizes to any number of intervals.

We have experimented with both approaches and found that they give very similar results. Here, we only present results using the Hurd-Rohwedder approach 6

After computing subjective means and standard deviations of nominal returns, we transform them by correcting for inflation and the risk-free return so as to obtain the subjective real risk premium and subjective standard deviation of real excess returns. For consistency with the subjective expectations about stock returns, we should also use subjective expectations about inflation and the risk-free return. The HRS does not elicit subjective expectations about prices and the risk-free interest rate, but the Survey of Consumers (http://www.sca.isr.umich.edu/) does. The average subjective inflation rate reported by individuals in the Survey of Consumers over the period $2002-2010$ is $3.75 \%$. We use this value to compute the subjective real expected stock market returns from the subjective nominal stock market returns. The Survey of Consumers asks its respondents if they expect any change in interest rates during the next 12 months, but not what the expected interest rate will be. However, most respondents expect the interest rate in the coming year to be about the same as the interest rate in the past year. Therefore, in order to construct a proxy of the subjective real interest rate, we take the average nominal interest rate from 2002 to 2010 and correct it by the aforementioned expected inflation rate of $3.75 \%$. This returns a real interest rate of $0.3 \%$, which we use in the computation.

We discretize the distribution of risk premium into five intervals using the following rule

$$
\text { interval }\left\{\begin{array}{rr}
1 & \text { risk premium } \leq 0 \\
2 & 0<\text { risk premium } \leq 75^{\text {th }} \text { percentile } \\
3 & 75^{\text {th }} \text { percentile }<\text { risk premium } \leq 85^{\text {th }} \text { percentile } \\
4 & 85^{\text {th }} \text { percentile }<\text { risk premium } \leq 95^{\text {th }} \text { percentile } \\
5 & 95^{\text {th }} \text { percentile }<\text { risk premium } \leq 99^{\text {th }} \text { percentile }
\end{array}\right.
$$

and collapsing the distribution to the interval midpoints. Within each of these intervals, we then take terciles of the standard deviation and again collapse distributions to the interval midpoints. The advantage of having a discrete distribution with a small number of distinct values is that we do not have to add a state variable to the model. Instead, we run the model for each group separately and aggregate the results afterwards, which is much less burdensome computationally. We pool individuals with zero or negative subjective risk premia in the same group since their optimal

\footnotetext{
${ }^{6}$ We use basic probability rules to identify inconsistent answers. First, we drop self-reported probabilities that are outside the $[0,1]$ interval. It should be noted that the procedure suggested by Dominitz and Manski (2007) implies that only values strictly greater than 0 and strictly less than 1 can be used. Given that a significant fraction of the respondents clusters at 0 or 1, we approximate a "zero probability" with 0.001 and a "one probability" with 0.999 . This allows us to retain most of the selected individuals in the sample when estimating subjective distributions of returns. The Hurd-Rohwedder approach does not require this approximation as it can be implemented for probabilities taking value 0 or 1 . Second, when two or more probabilities are elicited, we define as inconsistent all answers that do not conform to the probabilities of the single events and their union. If, for instance P0 and P10 are asked, we define as inconsistent all answers for which P0 $\leq$ P10. In this case, we only use P0 and ignore P10. The inequality above is required to be strict under the Dominitz-Manski approach, but not under the Hurd-Rohwedder approach.
} 
Table 5: Estimated distributions of subjective risk premium and volatility

\begin{tabular}{|c|c|c|c|c|c|c|c|c|c|c|c|}
\hline \multicolumn{3}{|c|}{2002} & \multicolumn{3}{|c|}{ 2004-2006 } & \multicolumn{3}{|c|}{2008} & \multicolumn{3}{|c|}{2010} \\
\hline $\mathrm{RP}$ & $\mathrm{SD}$ & Fraction & $\mathrm{RP}$ & $\mathrm{SD}$ & Fraction & $\mathrm{RP}$ & $\mathrm{SD}$ & Fraction & $\mathrm{RP}$ & SD & Fraction \\
\hline$\leq 0$ & 14.4 & 60.0 & $\leq 0$ & 16.8 & 68.4 & $\leq 0$ & 17.9 & 68.7 & $\leq 0$ & 16.5 & 63.2 \\
\hline \multirow[t]{3}{*}{.09} & 11.2 & 15.0 & 1.6 & 18.9 & 6.6 & 1.8 & 14.5 & 3.1 & 2.6 & 13.8 & 4.0 \\
\hline & & & & 19.2 & 0.4 & & 20.2 & 2.0 & & 21.1 & 4.0 \\
\hline & & & & & & & 23.7 & 2.6 & & 28.7 & 4.0 \\
\hline \multirow{3}{*}{3.7} & 10.4 & 3.5 & 4.0 & 17.5 & 5.8 & 5.1 & 11.8 & 3.3 & 7.0 & 12.8 & 3.7 \\
\hline & 17.4 & 3.5 & & 18.1 & 4.2 & & 18.8 & 3.2 & & 21.9 & 3.1 \\
\hline & 19.3 & 3.2 & & 18.6 & 0.6 & & 23.7 & 3.2 & & 27.9 & 3.3 \\
\hline \multirow[t]{3}{*}{9.4} & 12.4 & 3.5 & 8.7 & 15.6 & 9.9 & 10.0 & 12.5 & 5.6 & 11.9 & 12.8 & 3.3 \\
\hline & 16.5 & 3.5 & & & & & 17.2 & 1.1 & & 18.9 & 3.3 \\
\hline & 18.2 & 3.1 & & & & & 22.9 & 3.3 & & 24.7 & 3.3 \\
\hline \multirow[t]{3}{*}{15.6} & 8.0 & 2.6 & 12.6 & 10.7 & 3.7 & 17.2 & 10.5 & 1.3 & 19.2 & 5.6 & 1.7 \\
\hline & 9.6 & 0.9 & & 11.8 & 0.4 & & 17.2 & 1.3 & & 10.7 & 1.6 \\
\hline & 12.2 & 1.2 & & & & & 23.9 & 1.3 & & 21.4 & 1.6 \\
\hline
\end{tabular}

$\mathrm{RP}=$ subjective risk premium $(\mu), \mathrm{SD}=$ subjective volatility $\left(\sigma_{\epsilon}\right)$, Fraction $=$ fraction of the population

decision is to never invest in stocks. Also, because of ties, the grouping of standard deviation values does not always result in exactly one third of the sample, and we do not always have three different groups within each risk premium interval.

The resulting distributions are presented in Table 5. A large fraction of respondents (more than 60\%) is very pessimistic about stock market returns and expects them to earn less than the risk-free rate. The fraction varies between waves, though, and appears to be related to the business cycle, with the highest fraction of pessimistic individuals observed during the recent financial crisis (2008) $!^{7}$ The distributions are also skewed to the right, with noticeable fractions of respondents expecting risk premia of up to $20 \%$ (even more so in the nondiscretized data). Our findings-more pessimistic expectations about stock market gains than historical averages, high degree of heterogeneity in subjective expectations, and reported beliefs linked to the recent stock market performance—are in line with those documented by Hurd (2009).

\section{Model predictions with subjective expectations}

We now analyze the extent to which replacing rational expectations based on historical returns with subjective return expectations affects the model's predictions about household stock holding at both the intensive and extensive margins. We will also gauge the robustness of such predictions

\footnotetext{
${ }^{7}$ Cross-wave comparisons are subject to the caveat that expectations are elicited by different questions. For instance, HRS respondents are only asked about P0 in 2004 and 2006, while they report P0, P20 and P[-20] in 2010.
} 
to different values of key preference parameters (e.g., degree of risk aversion) and quantify the welfare implications of portfolio choices induced by subjective beliefs about future market returns that diverge from rational expectations based on historical returns. Throughout this section, we perform simulations using the subjective expectations for computing the decision rules of the individuals and the historical returns for generating actual returns.

We present results using the most recent available subjective expectations from the year 2010 . We have also simulated the model taking the subjective expectations from other years. The simulated investment patterns are qualitatively and quantitatively similar to the ones shown here and will be made available upon request to the authors.

Figure 10 shows stock market participation and share of stocks conditional on stock holding. Stock market participation is now substantially below 1 and in line with the empirical pattern observed in the data. Not surprisingly, in fact, the model predicts that all those who expect a negative risk premium (about 65\% of the sample) should not hold any stock. This leaves about $35 \%$ of stock owners, which is roughly what we see in the data. The fraction of wealth held in stocks is also matched more closely than under the assumption of rational expectations. Interestingly, the simulated profiles with subjective expectations are only marginally affected by the hypothesized degree of risk aversion. With subjective expectations, changing the coefficient of relative risk aversion from 4 to 1.5 implies an increase of 10 percentage points in the average share of risky assets over the simulation period. The same change causes the average share of risky assets to increase by 40 percentage points when it is assumed that individuals base their expectations on historical returns. It is worth pointing out that while the model predicts a virtually flat portfolio profile over time, the fraction of HRS household wealth invested in stocks is increasing in age.

Figure 11 compares wealth and consumption profiles generated by the model with subjective and historical returns. With a coefficient of relative risk aversion of 4, portfolio strategies generated by subjective returns produce wealth levels that are significantly below the level implied by investment choices under rational expectations. Over the simulation period, retirement wealth is $20 \%$ lower on average and consumption is $13 \%$ lower on average when portfolio choices are based on subjective rather than historical returns. As a result, we compute that if future stock market realizations follow the historical trend, but households portfolios are determined by subjective beliefs, the welfare loss (in utility terms) is $12 \%$. With a degree of risk aversion of 1.5 , individuals are substantially less conservative and tend to run down their assets relatively quickly. In this scenario, subjective beliefs about future risk premia that diverge from the historical trend induce wealth and consumption losses of $15 \%$ and $8 \%$, respectively, and a welfare loss of about $2 \%$. In general, the welfare loss associated with "inaccurate" return expectations is higher, the higher the degree of risk aversion. This is because higher risk aversion implies more conservative behaviors and a higher preference for accumulating a buffer stock to hedge against background risks. As a consequence, any missed investment opportunity due to overpessimistic expectations and unrealized investment returns due to overoptimistic beliefs translate into a higher welfare cost due to the need of reducing consumption and maintaining a sufficiently high level of wealth. 
Figure 10: Simulated investment behavior under subjective and historical returns; subjective expectations from 2010

Relative risk aversion $=1.5$
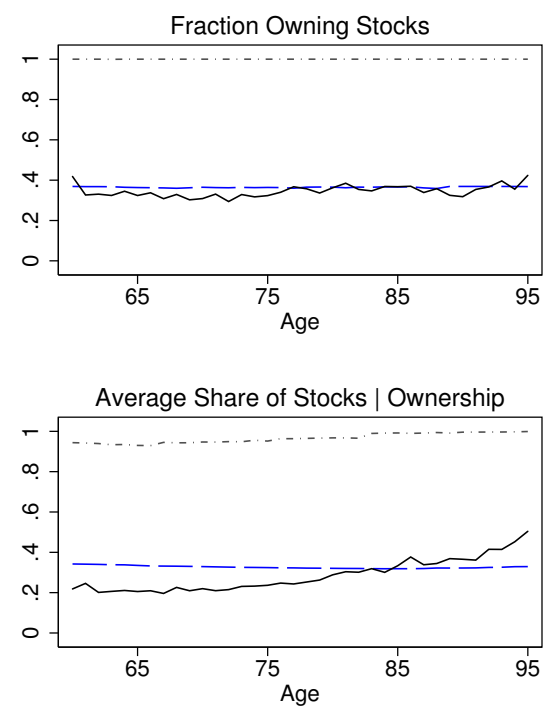

Subjective Returns
Relative risk aversion $=4.0$
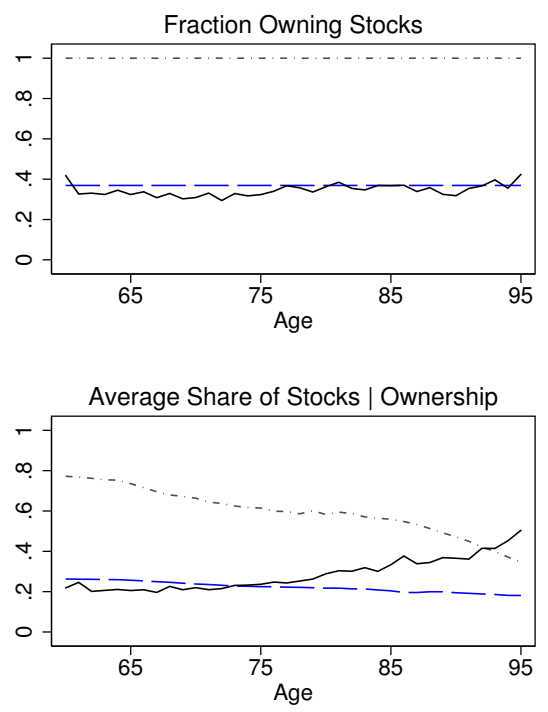

HRS

Figure 11: Simulated wealth and consumption profiles under subjective and historical returns; subjective expectations from 2010

Relative risk aversion $=1.5$
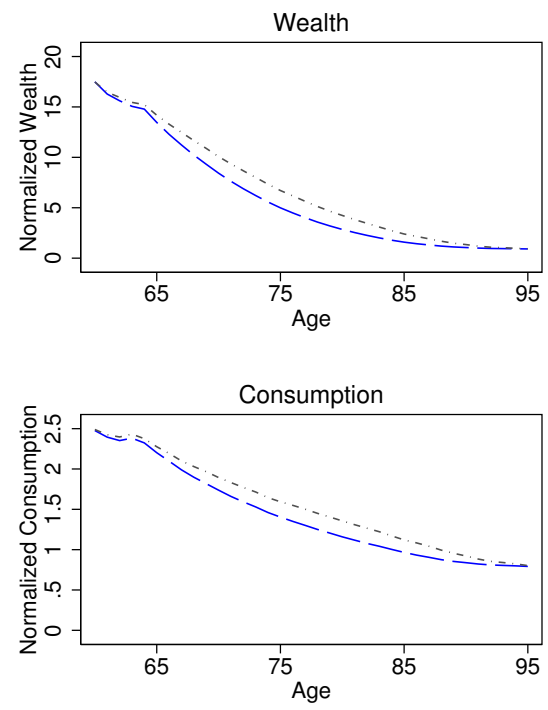

Relative risk aversion $=4.0$
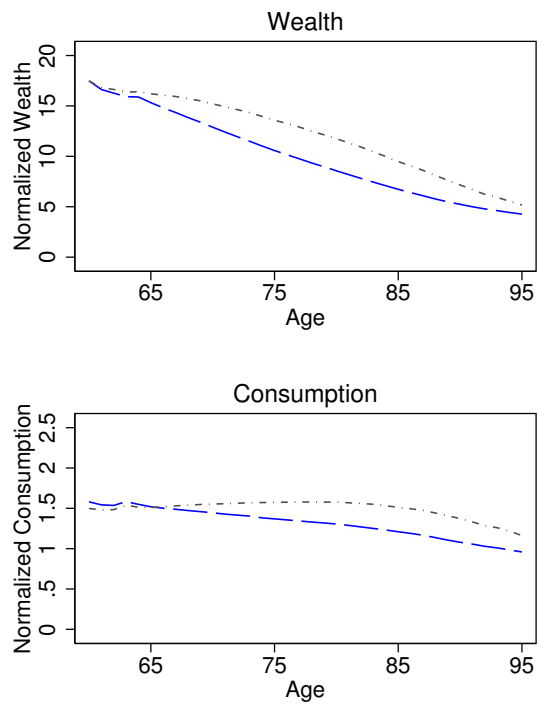

- - - Subjective Returns

_...... Historical Returns 
Figure 12: Simulated investment behavior under subjective and historical returns, using only financial wealth; subjective expectations from 2010

Relative risk aversion $=1.5$
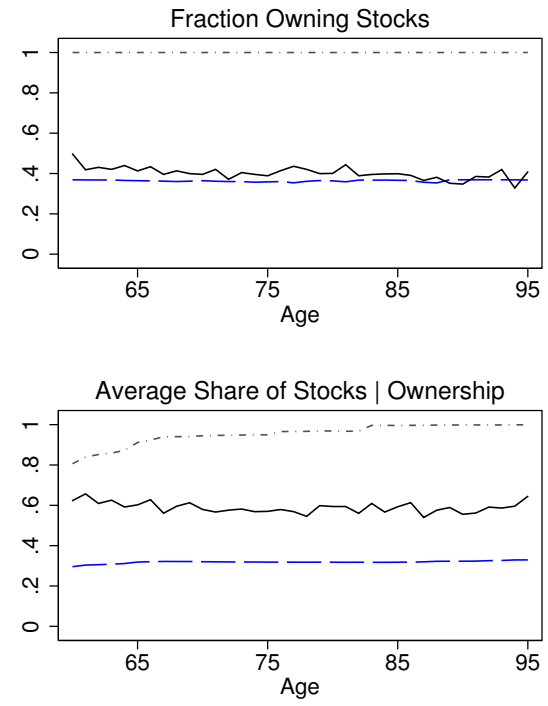

- - - Subjective Returns
Relative risk aversion $=4.0$
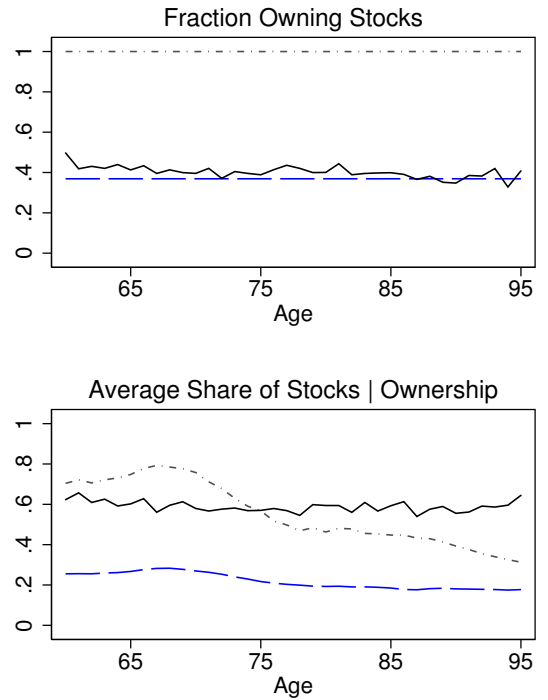

HRS

\section{Robustness Checks}

In this section, we describe the outcomes of two robustness checks. First, we document the extent to which our results are sensitive to the way household wealth is defined. Second, we explore an alternative measure of historical returns based on the last 10 years instead of the last 50 .

So far we have adopted a very comprehensive measure of household total wealth. In doing so, we have implicitly treated housing as a liquid and risk-free form of wealth, which individuals may tap into to finance their consumption during retirement. Although there is some evidence that American homeowners move out of their owned home in later life and tend to downsize their housing consumption during retirement (Banks, Blundell, Oldfield, \& Smith, 2010), the vast majority of individuals may be reluctant to spend down their housing equity due to large financial and social transaction costs, price volatility, and emotional attachment to their home. We therefore repeat our simulation exercises using only financial wealth-including the net value of stocks, bonds, checking and savings accounts, treasury securities, and IRAs-as a measure of household wealth. In our simulation sample, the ratio of financial wealth to retirement income is about 7 as opposed to a value of 17 for the ratio of total wealth to retirement income. This shows that most of household wealth is held in the form of housing and other non-perfectly liquid assets such as vehicles and businesses.

Figure 12 shows that using this alternative measure of wealth does not change the predictions 
Figure 13: Simulated wealth and consumption profiles under subjective and historical returns, using only financial wealth; subjective expectations from 2010

Relative risk aversion $=1.5$
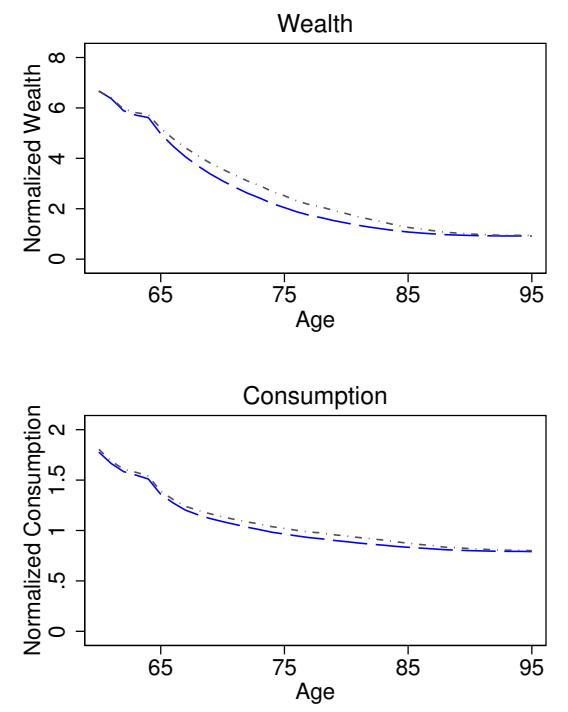

Relative risk aversion $=4.0$
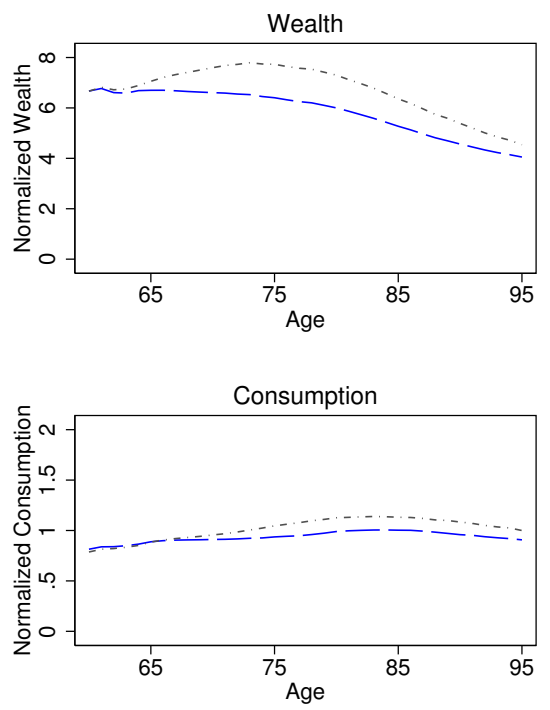

- - Subjective Returns

-... Historical Returns

regarding stock ownership appreciably: the top panel of this figure is very similar to the top panel of Figure 10. However, the picture for the average share of wealth invested in stocks is very different. Conditional on stock holding, the fraction of financial wealth invested in stocks in the data is constant across age at about $60 \%$. This pattern is qualitatively well replicated by the model with subjective expectations, but the model predicts a much lower average share of financial wealth in stocks, even at the relatively low relative risk aversion of 1.5. In contrast, the model with expectations based on historical returns predicts very different patterns with age, but predicts the average level better with a relative risk aversion of 4 .

Figure 13 presents the corresponding simulated wealth and consumption profiles. Comparing these profiles with those in Figure 11, we see that wealth at the beginning of the simulation span is much lower. This is because financial wealth accounts, on average, for about $40 \%$ of household total wealth. In this scenario the propensity to keep a buffer stock of wealth to hedge against the risk of disastrous medical costs at the very end of life remains similar. The size of this buffer stock is directly linked to the degree of relative risk aversion and, therefore, to the strength of the precautionary motive to save. Hence, while individuals with a degree of risk aversion of 1.5 deplete their financial wealth almost completely by the age of 95 , individuals with a degree of risk aversion of 4 maintain a buffer stock of wealth equivalent to more than four times their retirement income at the age of 95. The welfare implications of having subjective return expectations that diverge from the historical trend are similar to those discussed in the previous section, although welfare losses are now more modest. When portfolio choices are informed by subjective beliefs 
as observed in 2010 rather than by expectations based on historical returns the average welfare loss is $6 \%$, for a coefficient of relative risk aversion of 4 , and $1 \%$, for a coefficient of relative risk aversion of 1.5 .

In Figures 14 and 15 we present the simulation results when historical returns are computed using only the last 10 years as opposed to the last 50 years. As for household wealth, we return to the baseline measure of total wealth including housing, financial wealth, and other assets. Over the period 2001-2011, risk-free assets have given a real return of $-0.23 \%$, with inflation at $2.5 \%$. The average real risk premium has been $1.3 \%$ and the standard deviation of the real risk premium has been 0.19 . Investing in stocks becomes clearly less appealing with this distribution of stock market returns than with the distribution used in section 6. Indeed, this is what we observe when we solve and simulate the model assuming that agents hold expectations based on returns over the last 10 years and that the actual returns also follow this distribution. Specifically, while the model still predicts a $100 \%$ stock market participation rate, the average optimal share of risky assets is much smaller. With a coefficient of relative risk aversion of 1.5, the risky share is about $50 \%$, versus the $95 \%$ in Figure 7. With a coefficient of relative risk aversion of 4, the low risk premium coupled with high volatility significantly inhibits stock market investments. In this case, the average optimal share of risky assets is less than $20 \%$, as opposed to an average of $57 \%$ in Figure 7

As in the previous section, the model using subjective expectations replicates empirical stock market participation patterns very well, but fails to reproduce the increase with age in the fraction of household wealth held in stocks. More interesting are the simulated wealth and consumption profiles in Figure 15. When historical returns refer to the last 10 years, the effect of implementing portfolio strategies informed by subjective beliefs about wealth and consumption is rather small, and so is the overall impact on individual well-being. In particular, we find a welfare loss of $3 \%$ when the coefficient of relative risk aversion is equal to 4 , and a virtually zero welfare loss $(0.04 \%)$, when the coefficient of relative risk aversion is 1.5 .

\section{Discussion}

Standard life-cycle models of economic behavior predict that essentially everybody should invest in risky assets to some extent, which is greatly at odds with the less than $40 \%$ of households that are observed to own stocks in the data. Moreover, conditional on stock holding, standard models with realistic values of preference parameters predict much higher fractions of wealth invested in risky assets than we observe in the data. Several explanations have been put forward in the literature, but none has been able to fully reconcile theoretical predictions with observed empirical patterns.

In this paper, we explore to what extent subjective expectations about stock market returns that differ from historical returns can address the so-called "stock-market participation puzzle". We embed subjective expectations in an otherwise relatively standard economic life-cycle model. Using data on subjective expectations from the Health and Retirement Study, we show that a large fraction of the population holds beliefs that are so pessimistic that they should never invest in 
Figure 14: Simulated investment behavior under subjective and historical returns; subjective expectations from 2010; historical returns from 2001-2011

Relative risk aversion $=1.5$
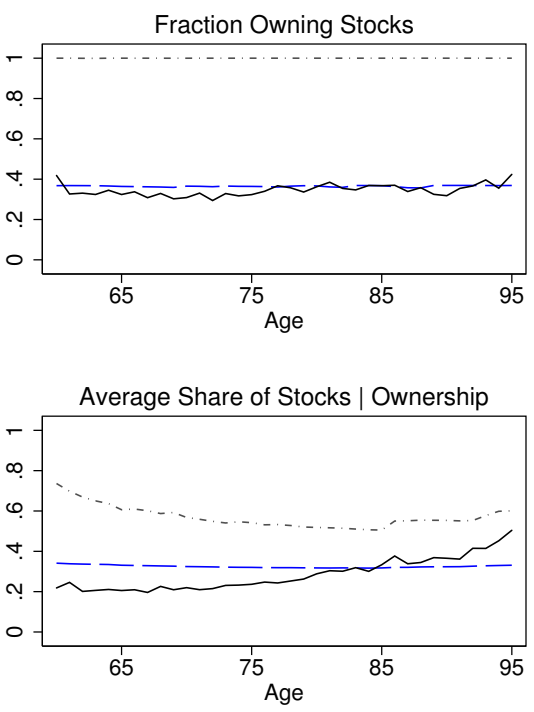

Relative risk aversion $=4.0$
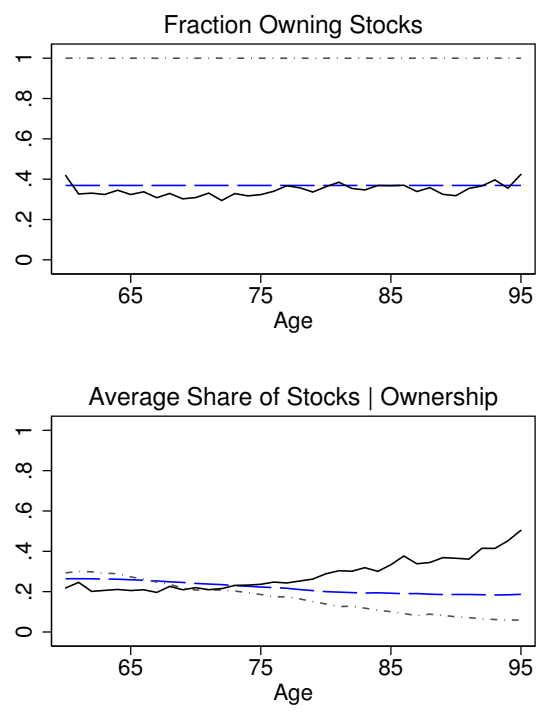

Subjective Returns

Historical Returns

HRS

Figure 15: Simulated wealth and consumption profiles under subjective and historical returns; subjective expectations from 2010; historical returns from 2001-2011

Relative risk aversion $=1.5$
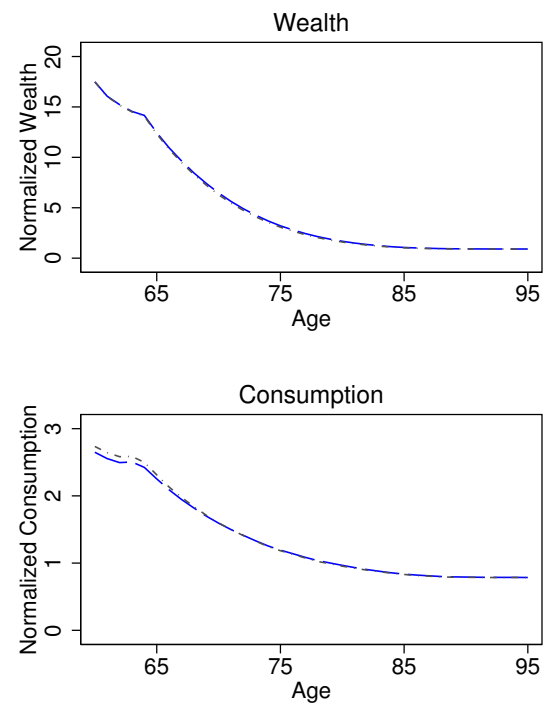

Relative risk aversion $=4.0$
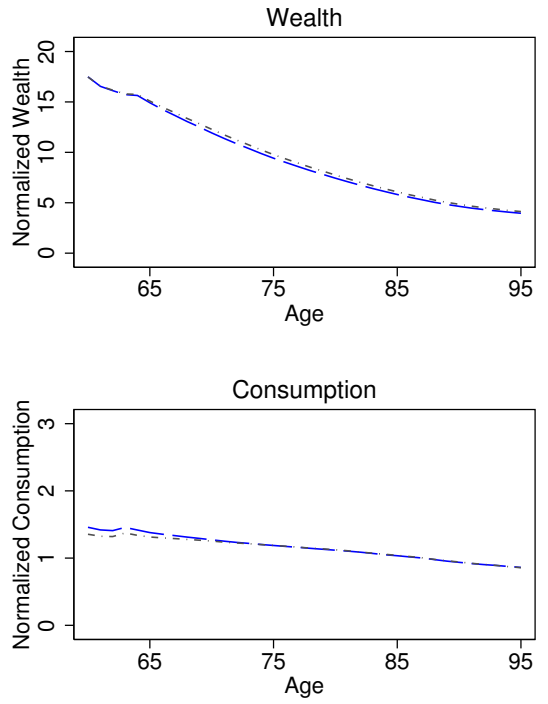

- - - Subjective Returns

-..... Historical Returns 
stocks. Of the remaining individuals, a nonnegligible fraction is very optimistic and they should invest almost all of their wealth in risky assets. A "moderate" middle group rounds out the distribution and is predicted to keep some but not all of its wealth in risky assets. The model with these heterogeneous subjective expectations is remarkably well able to match the empirical patterns in household stock market participation. However, the matching of observed portfolio shares is less satisfactory. In particular, while the model predicts that portfolio shares should gradually decrease over time, the fraction of wealth invested in stocks slightly increases with age in the data. Most likely this is a selection effect due to running down different asset categories, stock holding, and mortality being correlated.

Our model simulations also show that when subjective beliefs diverge from historical returns, portfolio choices informed by the former have important welfare consequences. We estimate welfare losses ranging from $3 \%$ to $12 \%$, depending on the degree of individual risk aversion and the way historical returns are computed. We also find that welfare losses are larger, the higher the degree of risk aversion.

These results have profound policy implications. Misperception about stock market returns can be attacked by various forms of education, information, and exemplary behavior. Although misperceptions are likely to be persistent and such a program will not reach everyone, there is a large scope for such programs. Not only government and non-profit organizations may be interested in this, but also commercial enterprises, in particular financial institutions.

An important aspect that is still missing from the model is the evolution of subjective expectations. The current model assumes that different individuals may have different expectations, but they keep the same expectations throughout their lifetimes. In practice, optimistic individuals who consume much and expect the asset returns to support their life style may notice a systematic rundown of their assets caused by lower returns than expected. They may respond to this by updating their expectations and behaving more cautiously in later life. Moreover, we have seen that in the data, subjective expectations vary between waves and may be related to the business cycle. This suggests a role for the business cycle in changing expectations as well.

Our model contains risks of medical expenses as estimated from the HRS data. If individuals hold beliefs about their likelihood of being in good health or about the risks of large medical expenses conditional on health status that are different from historical distributions, these may also impact individuals' behavior. We have performed limited experiments with subjective distributions of health transitions, but these did not have much effect on the results. However, it is worthwhile to study this more systematically and focus on expectations about out-of-pocket medical expenses directly.

\section{Acknowledgments}

This study was funded by the Social Security Administration through the University of Michigan Retirement Research Center (MRRC), grant number UM12-13. We would like to thank seminar participants at Erasmus University Rotterdam, VU University Amsterdam, the 2012 MRRC Researcher Workshop, the IMT Institute for Advanced Studies Lucca, and the All California Labor 
Conference 2012 for helpful comments and stimulating discussions.

\section{Appendix}

\section{A Normalization}

Consider the model set-up of section 2 . Define $c_{t}=C_{t} / P$. Then expected remaining lifetime utility (1) is

$$
U_{t}=P^{1-\gamma}\left[\frac{c_{t}^{1-\gamma}}{1-\gamma}+\mathrm{E}_{t}\left(\sum_{j=t+1}^{T_{M}} \beta^{j-t} \frac{c_{j}^{1-\gamma}}{1-\gamma}\right)\right],
$$

and, using the definition of cash on hand $X_{t}$ in the text, and $x_{t}=X_{t} / P$ and hc $\mathrm{h}_{t}=\mathrm{HC}_{t} / P$, the wealth transition (11) can be rewritten in the form (14). Clearly, $P$ does not play any role in the utility function, and it is eliminated from the wealth transition equation. By assuming that $\delta_{1}=1$ in the health cost model (6), this model can also be expressed in terms of the normalized health cost hc ${ }_{t}$, with $P$ not playing an independent role. Survival and health transition equations and other restrictions also do not depend on $P$. Thus, exploiting the scale-independence of the original maximization problem, we can rewrite all variables as ratios to the constant flow of retirement income so to reduce the dimensionality of the problem from 3 state variables to 2 . This renormalization, introduced by Carroll (1992, 1997), makes the numerical problem more tractable as it significantly decreases the computational burden. Carroll (1992, 1997) shows that this normalization can even be done if income is variable and uncertain, at least within the income transition model he considers, but our model is much simpler because we only consider retirees and assume they have a constant stream of income.

\section{B Numerical solution}

The model is solved via backward induction. Let $u_{t}=U_{t} / P^{1-\gamma}$ be the normalized expected remaining lifetime utility and define the value function

$$
v_{t}\left(x_{t}, H_{t}\right) \equiv \max u_{t}
$$

where the maximization is done over all decision variables. In the final period $T=100$, expected remaining lifetime utility is $u_{T}=c_{T}^{1-\gamma} /(1-\gamma)$. This is maximized when $c_{t}$ is maximized. With the restriction $W_{T+1} \geq 0$ and income, taxes, and health costs also being zero, if follows from (14) that utility is maximized by $c_{T}=x_{T}$ and the value function is

$$
v_{T}\left(x_{T}, H_{T}\right)=\frac{x_{T}^{1-\gamma}}{1-\gamma} .
$$


Now consider the period $T-1$ problem. Normalized cash on hand $x_{T-1}$ and health status $H_{T-1}$ are given and the agent maximizes

$$
u_{T-1}=\frac{c_{T-1}^{1-\gamma}}{1-\gamma}+\beta \sum_{g \in\{\text { good,bad }\}} S\left(T, g \mid T-1, H_{T-1}\right) \mathrm{E}_{T-1}\left(\frac{c_{T}^{1-\gamma}}{1-\gamma} \mid \text { alive }_{T}, H_{T}=g\right) .
$$

Whatever the choice at age $T-1$ and realizations of the health transition and health cost processes, if the individual is still alive at age $T$, he or she will choose $c_{T}=x_{T}$ and remaining lifetime utility will be $v_{T}\left(x_{T}, H_{T}\right)$. Thus, the problem at age $T-1$ becomes the problem of maximizing

$$
u_{T-1}=\frac{c_{T-1}^{1-\gamma}}{1-\gamma}+\beta \mathrm{E}_{T-1}\left[v_{T}\left(x_{T}, H_{T}\right)\right]
$$

over the decision variables $c_{T-1}$ and $\alpha_{T-1}$. Note that the expectation now includes the survival probability. The maximized value of $u_{T-1}$ is $v_{T-1}\left(x_{T-1}, H_{T-1}\right)$. Walking backwards, the argument can now be repeated for $T-2, \ldots, t_{0}$, and the problem at time $t$ can be rephrased recursively as

$$
v_{t}\left(x_{t}, H_{t}\right)=\max _{c_{t}, \alpha_{t}}\left\{\frac{c_{t}^{1-\gamma}}{1-\gamma}+\beta \mathrm{E}_{t}\left[v_{t+1}\left(x_{t+1}, H_{t+1}\right)\right]\right\} .
$$

The value function at age $t+1$ can be used to compute the optimal decision rules in period $t$. This procedure is iterated backwards to the initial period $t=60$.

In order to implement this solution algorithm, we discretize the continuous state variable, normalized cash-on-hand, by defining an equally spaced grid, $\left\{x_{k}\right\}_{k=1}^{K}$. The upper bound is chosen to be nonbinding in all periods, specifically $x_{K}=99$. The lower bound is set to 0.01 . This can be interpreted as a minimum level of consumption guaranteed by government transfers in all periods. By imposing $x_{t} \geq 0.01$ for all $t$, the model solution implicitly accounts for transfers from welfare programs that equal to $1 \%$ of retirement income plus medical expenses minus all available resources, if that amount is positive, and zero otherwise.

The optimization procedure combines a root-finding algorithm (Brent's method; Brent, 1973 , chapter 4) and standard grid search. For given values of $x_{t}$ and $H_{t}$, the value function is concave with respect to $c_{t}$. Thus, optimal normalized consumption can be computed using Brent's method, significantly improving on computational efficiency. It is not known whether the value function is concave in portfolio share $\alpha_{t}$. Hence, to avoid the potential danger of selecting local optima, we optimize over the space of the remaining decision variable using a standard grid search. For this purpose, we discretize the share of risky assets, $\alpha$, to take 11 equally spaced values in the interval $[0,1]$.

Interpolation plays a crucial role in the solution of the dynamic programming problem at hand. We use two-dimensional cubic splines interpolation to evaluate the value function between points on the cash-on-hand grid. Cubic splines have the advantage of being twice continuously differentiable with a nonzero third derivative. These properties preserve the prudence of the utility function, which plays an important role in precautionary savings and the effect of background risks on individual decisions (Eeckhoudt \& Kimball, 1992, Kimball, 1990). The strictly positive 
lower bound on the grid for cash-on-hand implies that the value function is also bounded from below. This makes the spline interpolation work very well as long as the discretization of the state space is sufficiently fine. Numerical integrations are performed by Gaussian quadrature.

\section{References}

Alan, S. (2006). Entry costs and stock market participation over the life cycle. Review of Economic Dynamics, 9, 588-611.

Ameriks, J., \& Zeldes, S. P. (2004). How do household portfolio shares vary with age? Mimeo, Columbia University, Graduate School of Business, New York, NY. Retrieved October 15, 2012, from http://www0.gsb.columbia.edu/whoswho/getpub.cfm?pub=16

Attanasio, O. P., \& Weber, G. (1993). Consumption growth, the interest rate and aggregation. Review of Economic Studies, 60, 631-649.

Attanasio, O. P., \& Weber, G. (1995). On the aggregation of Euler equations for consumption in simple overlapping-generations models. Economica, 62, 565-576.

Banks, J., Blundell, R., Oldfield, Z., \& Smith, J. P. (2010). Housing price volatility and downsizing in later life. In D. A. Wise (Ed.), Research findings in the economics of aging (pp. 337-379). Chicago, IL: University of Chicago Press.

Bellman, R. (1957). Dynamic programming. Princeton, NJ: Princeton University Press. (Reprinted 2003 by Dover Publications, Mineola, NY)

Brent, R. P. (1973). Algorithms for minimization without derivatives. Englewood Cliffs, NJ: Prentice-Hall. (Reprinted 2002 by Dover Publications, Mineola, NY)

Campbell, J. Y. (2006). Household finance. Journal of Finance, 61, 1553-1604.

Campbell, J. Y., Cocco, J. F., Gomes, F. J., \& Maenhout, P. J. (2001). Investing retirement wealth: A life-cycle model. In J. Y. Campbell \& M. Feldstein (Eds.), Risk aspects of investment-based Social Security reform (pp. 439-482). Chicago, IL: University of Chicago Press.

Carroll, C. D. (1992). The buffer-stock theory of saving: Some macroeconomic evidence. Brookings Papers on Economic Activity, 1992(2), 61-156.

Carroll, C. D. (1997). Buffer-stock saving and the life cycle/permanent income hypothesis. Quarterly Journal of Economics, 112, 1-55.

Cocco, J. F., Gomes, F. J., \& Maenhout, P. J. (2005). Consumption and portfolio choice over the life cycle. Review of Financial Studies, 18, 491-533.

Congressional Budget Office [CBO]. (2010). Average federal tax rates in 2007. Washington, DC: Congressional Budget Office. Retrieved September 9, 2012, from http://www.cbo.gov/sites/default/files/cbofiles/ftpdocs/115xx/doc11554/ averagefederaltaxrates2007.pdf

Curcuru, S., Heaton, J., Lucas, D., \& Moore, D. (2010). Heterogeneity and portfolio choice: Theory and evidence. In Y. Aït-Sahalia \& L. P. Hansen (Eds.), Handbook of financial econometrics (pp. 337-382). Amsterdam, Netherlands: North-Holland. 
De Nardi, M., French, E., \& Jones, J. B. (2010). Why do the elderly save? The role of medical expenses. Journal of Political Economy, 118, 39-75.

Dominitz, J., \& Manski, C. F. (2007). Expected equity returns and portfolio choice: Evidence from the Health and Retirement Study. Journal of the European Economic Association, 5, 369-379.

Eeckhoudt, L., \& Kimball, M. (1992). Background risk, prudence and the demand for insurance. In G. Dionne (Ed.), Contributions to insurance economics (pp. 239-254). New York, NY: Springer.

French, E. (2005). The effects of health, wealth, and wages on labour supply and retirement behaviour. Review of Economic Studies, 72, 395-427.

French, E., \& Jones, J. B. (2004). On the distribution and dynamics of health care costs. Journal of Applied Econometrics, 19, 705-721.

Gomes, F., Michaelides, A., \& Polkovnichenko, V. (2009). Optimal savings with taxable and tax-deferred accounts. Review of Economic Dynamics, 12, 718-735.

Gourinchas, P.-O., \& Parker, J. A. (2002). Consumption over the life cycle. Econometrica, 70, 47-89.

Guiso, L., Jappelli, T., \& Terlizzese, D. (1996). Income risk, borrowing constraints, and portfolio choice. American Economic Review, 86, 158-172.

Guiso, L., Sapienza, P., \& Zingales, L. (2008). Trusting the stock market. Journal of Finance, 63, 2557-2600.

Gustman, A. L., Steinmeier, T. L., \& Tabatabai, N. (2010). Pensions in the Health and Retirement Study. Cambridge, MA: Harvard University Press.

Haliassos, M., \& Bertaut, C. C. (1995). Why do so few hold stocks? Economic Journal, 105, $1110-1129$.

Haliassos, M., \& Michaelides, A. (2003). Portfolio choice and liquidity constraints. International Economic Review, 44, 143-177.

Heaton, J., \& Lucas, D. (2000). Portfolio choice in the presence of background risk. Economic Journal, 110, 1-26.

Hochguertel, S. (2003). Precautionary motives and portfolio decisions. Journal of Applied Econometrics, 18, 61-77.

Hong, H., Kubik, J. D., \& Stein, J. C. (2004). Social interaction and stock-market participation. Journal of Finance, 59, 137-163.

Hubbard, G., Skinner, J., \& Zeldes, S. (1995). Precautionary saving and social insurance. Journal of Political Economy, 103, 360-399.

Hung, A. A., Meijer, E., Mihaly, K., \& Yoong, J. (2009). Building up, spending down: Financial literacy, retirement savings management, and decumulation (Working Paper No. WR-712). Santa Monica, CA: RAND Corporation.

Hurd, M. D. (1989). Mortality risk and bequests. Econometrica, 57, 779-813.

Hurd, M. D. (2002). Portfolio holdings of the elderly. In L. Guiso, M. Haliassos, \& T. Jappelli (Eds.), Household portfolios (pp. 431-472). Cambridge, MA: MIT Press.

Hurd, M. D. (2009). Subjective probabilities in household surveys. Annual Review of Economics, $1,543-562$. 
Hurd, M. D., \& Rohwedder, S. (2011). Stock price expectations and stock trading. Mimeo, RAND Corporation, Santa Monica, CA.

Hurd, M. D., Van Rooij, M., \& Winter, J. (2011). Stock market expectations of Dutch households. Journal of Applied Econometrics, 26, 416-436.

Juster, F. T., \& Suzman, R. (1995). An overview of the Health and Retirement Study. Journal of Human Resources, 30, S7-S56.

Kézdi, G., \& Willis, R. J. (2008). Stock market expectations and portfolio choice of American households. Mimeo, University of Michigan, Ann Arbor.

Kimball, M. S. (1990). Precautionary saving in the small and in the large. Econometrica, 58, 53-73.

Korniotis, G. M., \& Kumar, A. (2011). Do older investors make better investment decisions? Review of Economics and Statistics, 93, 244-265.

Lee, J., Kapteyn, A., Meijer, E., \& Yang, J.-S. (2010). Pre- and post-retirement asset portfolios (Publication No. 213). Madison, WI: Filene Research Institute.

Lockwood, L. M. (2012). Bequest motives and the annuity puzzle. Review of Economic Dynamics, 15, 226-243.

Merton, R. C. (1969). Lifetime portfolio selection under uncertainty: The continuous-time case. Review of Economics and Statistics, 51, 247-257.

Paiella, M. (2007). The forgone gains of incomplete portfolios. Review of Financial Studies, 20, $1623-1646$.

Piketty, T., \& Saez, E. (2007). How progressive is the U.S. federal tax system? A historical and international perspective. Journal of Economic Perspectives, 21(1), 3-24.

Rosen, H. S., \& Wu, S. (2004). Portfolio choice and health status. Journal of Financial Economics, 72, 457-484.

Samuelson, P. A. (1969). Lifetime portfolio selection by dynamic stochastic programming. Review of Economics and Statistics, 51, 239-246.

Scholz, J. K., Seshadri, A., \& Khitatrakun, S. (2006). Are Americans saving "optimally" for retirement? Journal of Political Economy, 114, 607-643.

St.Clair, P., et al. (2011). RAND HRS data documentation, Version L. Santa Monica, CA: RAND Corporation.

Vissing-Jørgensen, A. (2002). Limited asset market participation and the elasticity of intertemporal substitution. Journal of Political Economy, 110, 825-853.

Yogo, M. (2009). Portfolio choice in retirement: Health risk and the demand for annuities, housing, and risky assets (Working Paper No. 2009-3). Chestnut Hill, MA: Center for Retirement Research at Boston College. 